Supporting information

\title{
Ru-Pd Thermoresponsive Nanocatalyst Based on Poly(ionic liquid) for Highly Efficient and Selectively Catalyzed Suzuki Coupling and Asymmetric Transfer Hydrogenation in the Aqueous Phase
}

Xinjuan Lia,*, Yanping Sun ${ }^{\mathrm{a}}$, Shangyue Wang ${ }^{\mathrm{a}}$, Xianbin Jia ${ }^{\mathrm{a}, *}$

a Henan Key Laboratory of Green Chemistry, Collaborative Innovation Center of Henan Province for Green Manufacturing of Fine Chemicals, Key Laboratory of Green Chemical Media and Reactions, Ministry of Education, School of Chemistry and Chemical Engineering, Henan Normal University, Xinxiang, 453007, P. R. China,

Correspondence to: Xinjuan Li(E-mail:) xinjuanli2009@163.com

Xianbin Jia (E-mail:)axbjia@163.com

Supporting information contains 27 pages (S1-S28)

Supporting information contains 5 tables (Table S1-S5)

Supporting information contains 13 figures (Figure S1-Figure S41) 


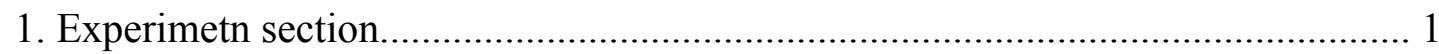

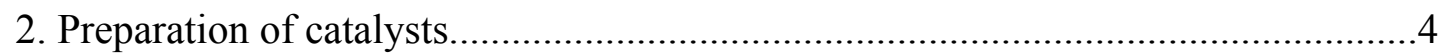

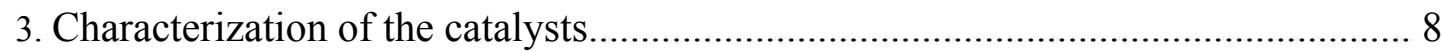

4. Catalysts used in asymmetric transfer hydrogenation and coupling

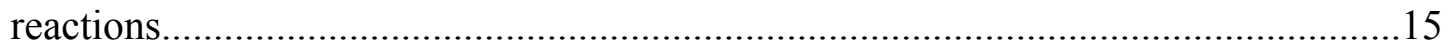

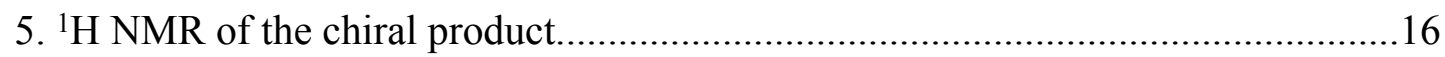

6. HPLC of racemate for catalytic product......................................................... 23 


\section{Experimental Section}

\subsection{Materials and Reagents.}

Methacrylicacid ( $>98 \%$, MAA, Aldin, China) was purifified by distillation under pressure. Azobis(isobutyronitrile) ( $>98 \%$, AIBN, Tianjin chemical reagent co, China) was recrystallized in ethanol. PIL-1 was prepared using previously described methods, ${ }^{1}$ and other chemical reagents were used as-received condition.

\subsection{Methods.}

${ }^{1} \mathrm{H}$ NMR spectra were measured on a Bruker $400 \mathrm{MHz}$ NMR spectrometer. A Thermo FLASH 1112 elemental analyzer was used to determine the elemental analysis. The IR measurements were carried out on a Fourier transform infrared spectrometer (Nicolet 94 NEXUS). HPLC method was performed on an Agilent TM 1100. The molecular weight and molecular weight distribution (PDI $=\mathrm{Mw} / \mathrm{Mn})$ of the synthesized polymer samples were determined by gel permeation chromatography (GPC) equipped with a Waters 1515 apparatus, DMF was used as eluent, the flow rate was $1.0 \mathrm{~mL} . \mathrm{min}$, and polystyrene samples were used as standards. Transmission electron microscopy (JEOL-2010, $200 \mathrm{kV}$ ) and field emission scanning electron microscopy (NovaNano SEM450) were used to characterize the morphology of the 
catalyst. TEM image at $60{ }^{\circ} \mathrm{C}$ refers to the preparation of the sample after it is dispersed in the solution $\left(\mathrm{H}_{2} \mathrm{O} / \mathrm{iPrOH}(\mathrm{v} / \mathrm{v}=1: 1)\right)$ and heated to $60{ }^{\circ} \mathrm{C}$, and then tested at room temperature. DSC was performed on a custom-made PCT-1A thermal analysis system. XPS spectra were obtained on a VG ESCALAB MK II spectrograph.

The average diameter (Dn) was determined using TEM and were calculated using the following formula:

$$
D_{n}=\sum_{i=1}^{k} n_{i} D_{i} / \sum_{i=1}^{k} n_{i}
$$

Where $\mathrm{k}$ was the total number of measured particles, Di was the measured particle diameter, and ni was the particle number with diameter Di.

\section{Preparation of catalysts}

\subsection{Synthesis of PILs}

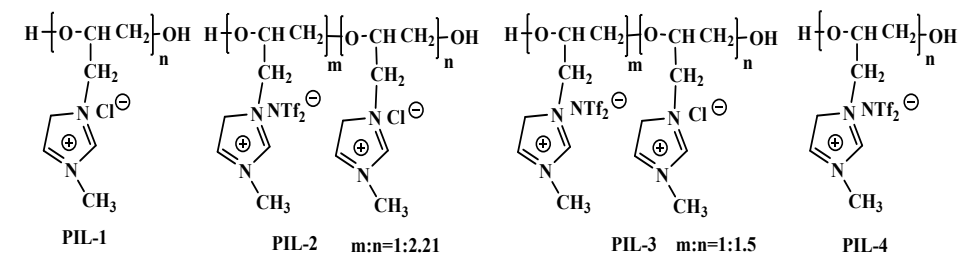

Fig.S1 The structure of PILs.

PIL was synthesized by the polyepichlorohydrin (PECH) and methylimidazole. As a typical experiment ${ }^{[1]}$, PECH $(1 \mathrm{~g}, 0.50 \mathrm{mmol})$ was added into a one-neck round bottom flask $(100 \mathrm{~mL})$, after being degassed for $30 \mathrm{~min}$, methylimidazole $(0.023 \mathrm{~g}$, $0.28 \mathrm{mmol}$ ) was added by syringe, the mole ratio of PECH to methylimidazole was 
1.8:1.0. Stirring until completely dissolved, the flask was sealed and immersed into an oil bath at $80{ }^{\circ} \mathrm{C}$ for $10 \mathrm{~h}$, and then the crude product (PIL-1) was collected by sediment in ether, washed several times with ether until no small molecule impurity was found and dried at $60^{\circ} \mathrm{C}$ under vacuum for $48 \mathrm{~h}$.

The PIL-2 with partial $\mathrm{Cl}^{-}$and partial $\left[\mathrm{NTf}_{2}\right]^{-}$was prepared by partial ion exchange with PIL-1. PIL-1 (29.30 g, $0.067 \mathrm{mmol})$ and $\operatorname{LiNTf}_{2}(9.62 \mathrm{~g}, 0.034 \mathrm{mmol})$ were dissolved in $100 \mathrm{~mL}$ distilled water and formed a clear mixture solution, with stirring at $25{ }^{\circ} \mathrm{C}$ for $5 \mathrm{~h}$, the insoluble oily substance was formed and collected by centrifugation, the crude product was washed with water and ether respectively, and dried at $60{ }^{\circ} \mathrm{C}$ under vacuum to use. The yield was $91.2 \%$.

The PIL-3 was prepared by partial ion exchange with PIL-1. PIL-1 (29.30 g, $0.067 \mathrm{mmol})$ and $\operatorname{LiNTf}_{2}(14.43 \mathrm{~g}, 0.051 \mathrm{mmol})$ were dissolved in $100 \mathrm{~mL}$ distilled water and formed a clear mixture solution, with stirring at $25^{\circ} \mathrm{C}$ for $5 \mathrm{~h}$, the insoluble oily substance was formed and collected by centrifugation, the crude product was washed with water and ether respectively, and dried at $60{ }^{\circ} \mathrm{C}$ under vacuum to use. The yield was $93.5 \%$.

The PIL-4 was prepared by full ion exchange with PIL-1. PIL-1 (29.30 g, 0.067 mmol) and $\operatorname{LiNTf}_{2}(22.96 \mathrm{~g}, 0.08 \mathrm{mmol})$ were dissolved in $100 \mathrm{~mL}$ distilled water and formed a clear mixture solution, with stirring at $25^{\circ} \mathrm{C}$ for $5 \mathrm{~h}$, the insoluble oily substance was formed and collected by centrifugation, the crude product was washed 
with water and ether respectively, and dried at $60^{\circ} \mathrm{C}$ under vacuum to use. The yield was $91.5 \%$.

2.2 Synthesis of polymerizable chiral ligand (1R, 2R)-N-p-vinyl-1,2-diphenylethylenediamine (V-TsDPEN)

The synthesis method was shown in Fig. S2. $1 \mathrm{~g}(1 \mathrm{R}, 2 \mathrm{R})-1$, 2-diphenylethylenediamine was added to $100 \mathrm{~mL}$ round-bottom flask, and $25 \mathrm{~mL}$ $\mathrm{CH}_{2} \mathrm{Cl}_{2}$ was added to dissolve it. After that, 20 drops of triethylamine were added into the flask, and then $1 \mathrm{~g}$ styrene sulfonyl chloride $/ 5 \mathrm{~mL} \mathrm{CH}_{2} \mathrm{Cl}_{2}$ was added to it in ice-water bath, stirred overnight at room temperature, insoluble substances were found. After extraction and filtration, washing with $5 \% \mathrm{NaOH}$ solution, drying, filtering, rotary steaming and dissolving with ether. The ether solution was obtained by extraction and filtration, and then $1 \mathrm{~mL}$ concentrated hydrochloric acid was added to the ether solution to obtain white precipitation. The white solid was filtered and washed with $5 \% \mathrm{NaOH}$ aqueous solution. The white solid was extracted three times with $\mathrm{CH}_{2} \mathrm{Cl}_{2}$ and combined with organic phase. The solvent was removed by rotating evaporation. V-TsDPEN was obtained after drying for $48 \mathrm{~h}$ in $62.0 \%$ yield.

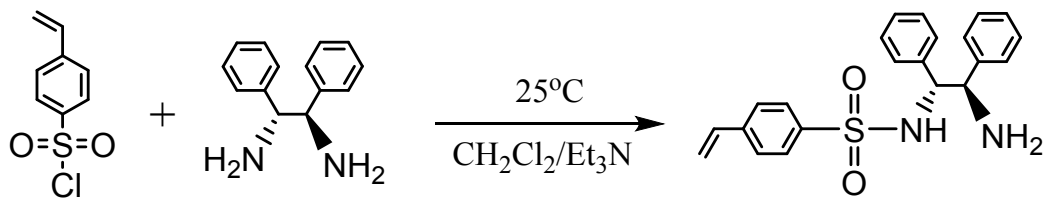

Fig. S2 The synthesized method of V-TsDPEN.

\subsection{Synthesis of V-TsDPEN-Ru}

The synthesis method was shown in Fig. S3. The chiral monomer V-TsDPEN 
$0.76 \mathrm{~g}$ was added in a $100 \mathrm{~mL}$ round bottom flask, and then $40 \mathrm{~mL}$ anhydrous dichloromethane was added to dissolve it. $20.61 \mathrm{~g}\left[\mathrm{RuCl}_{2}(\mathrm{p}\right.$-cymene) $]$ which was dissolved in $20 \mathrm{~mL}$ anhydrous dichloromethane was added the flask. After reaction for $10 \mathrm{~h}$ in argon atmosphere at room temperature, the solvent was removed by Spin evaporation. A mixed solvent of dichloromethane/ether=1/1 was added to remove the surplus $\left[\mathrm{RuCl}_{2}(\mathrm{p}\right.$-cymene) $)$ by stirring filtration. The filtrate was concentrated and precipitated in $n$-hexane. The product was filtered and washed with n-hexane. The product was vacuum dried at $25^{\circ} \mathrm{C}$ for $24 \mathrm{~h}$ with the yield of $84.1 \%$.
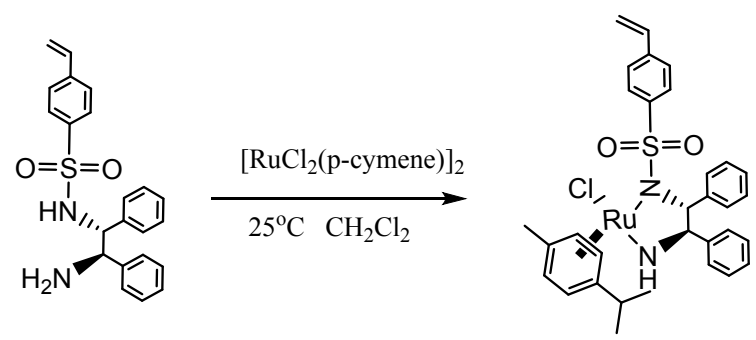

Fig. S3 The synthesized method of V-TsDPEN-Ru.

\subsection{Synthesis of copolymer}

The synthesis method was shown in Fig. S4. Chiral monomer V-TsDPEN-Ru (3 mmol) and methacrylic acid $(0.26 \mathrm{~g}, 3 \mathrm{mmol})$ were added to a $50 \mathrm{~mL}$ round bottom flask in turn. $6 \mathrm{~mL}$ DMF was added to the flask for ultrasonic dissolution. AIBN (4.92 $\mathrm{mg}, 0.06 \mathrm{mmol}$ ) was added after 5 minutes of argon gas introduction. After 30 minutes of argon gas introduction, the flask was sealed and the oil bath reacted for 48 $\mathrm{h}$ at $75{ }^{\circ} \mathrm{C}$. After the reaction stopped, a large number of white precipitates were obtained by precipitation in $60 \mathrm{~mL}$ ethanol. After centrifugation, the precipitates were washed repeatedly with anhydrous ethanol to remove the unpolymerized monomers. 
The white solid products were obtained by vacuum drying at $40{ }^{\circ} \mathrm{C}$ for $48 \mathrm{~h}$. The product was labeled as random copolymer with a yield of $88.3 \%$.

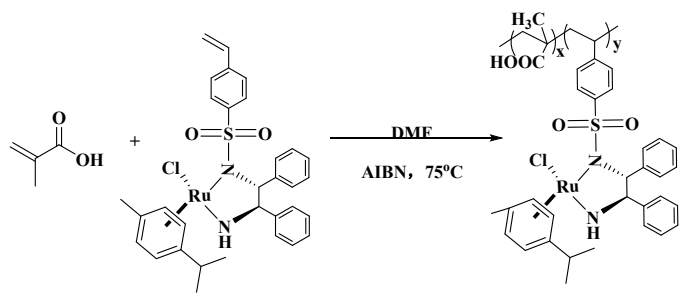

Fig. S4 The synthesized method of copolymer.

\subsection{Synthesis of Ru-catalysts}

The $0.247 \mathrm{~mL}$ ammonia water was injected into $50 \mathrm{~mL}$ ethanol solution with a syringe volume. Ethanol solution containing $0.5 \mathrm{wt} \%$ ammonia water (complex solvent) was prepared. The amplitude of sound wave of the NC ultrasonic cleaner was set at $40 \%$, and the complex solvent was put into the ultrasonic cleaner for 30 minutes. Accurately random copolymer $(0.9 \mathrm{mmol}, 0.21 \mathrm{~g})$ in $3 \mathrm{~mL}$ DMSO solution, and PIL-1 $(1.8 \mathrm{mmol})$ in $2 \mathrm{~mL}$ DMSO solution, was mixed and add them to the complex solution by dropping tube under the condition of ultrasound. A large number of PIL complexes precipitate quickly, and then the dropping is completed by ultrasound for 30 minutes, and then filter them. The impurities were removed by precipitation, ethanol washing and vacuum drying for $24 \mathrm{~h}$ at $40{ }^{\circ} \mathrm{C}$. The yield of $\mathrm{Ru}$ catalyst-1 was $73.2 \%$.

The preparation method of $\mathrm{Ru}$ catalyst- $2, \mathrm{Ru}$ catalyst- 3 and $\mathrm{Ru}$ catalyst- 4 is similar to that of Ru catalyst-1 expect using PIL-2, PIL-3 or PIL-4 not PIL-1. The yields of $\mathrm{Ru}$ catalyst- $2, \mathrm{Ru}$ catalyst-3 and $\mathrm{Ru}$ catalyst- 4 were $69.1 \%, 78.3 \%$ and 
$73.5 \%$ respectively.

\subsection{Synthesis of Ru-Pd catalysts}

Ru catalyst-1-4 (62.4 mg) was dissolved in $1 \mathrm{~mL}$ dimethyl sulfoxide (DMSO) with a $25 \mathrm{~mL}$ schlenk flask. Then the solution of palladiumacetate $(8.4 \mathrm{mg})$ in $1 \mathrm{~mL}$ DMSO was added dropwise to the solution. This reaction was carried out under nitrogen-filled conditions for $12 \mathrm{~h}$, and after completion of the reaction, sedimentation in ethyl ether, the crude product was settled in ethyl ether and washed with dichloroethane to remove unreacted raw materials.

\section{Characterization of the catalysts}

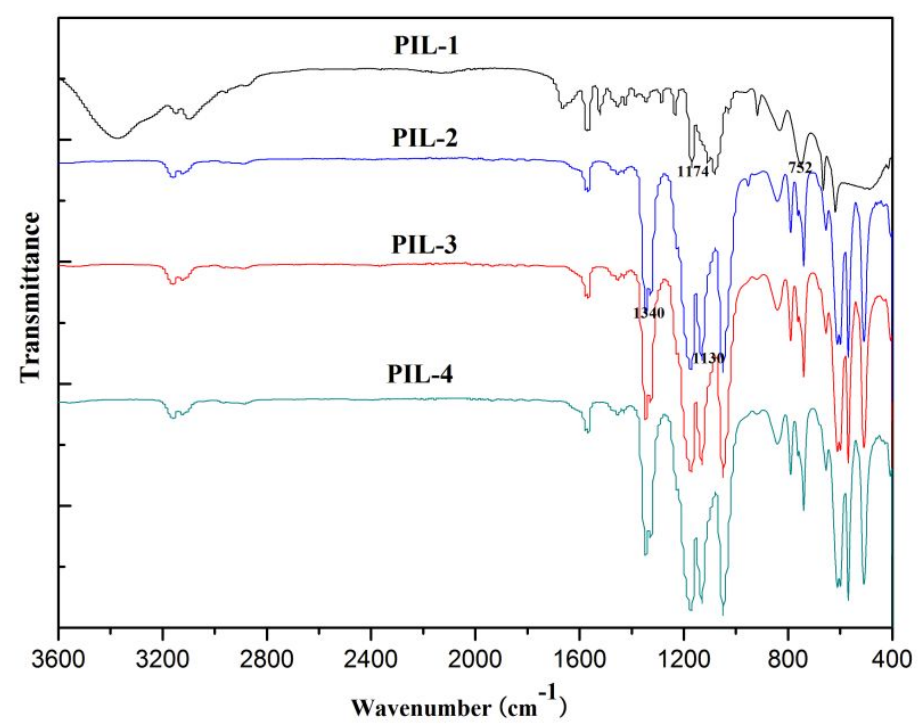

Fig. S5 Fourier transform infrared (FT-IR)spectra of PILs. 

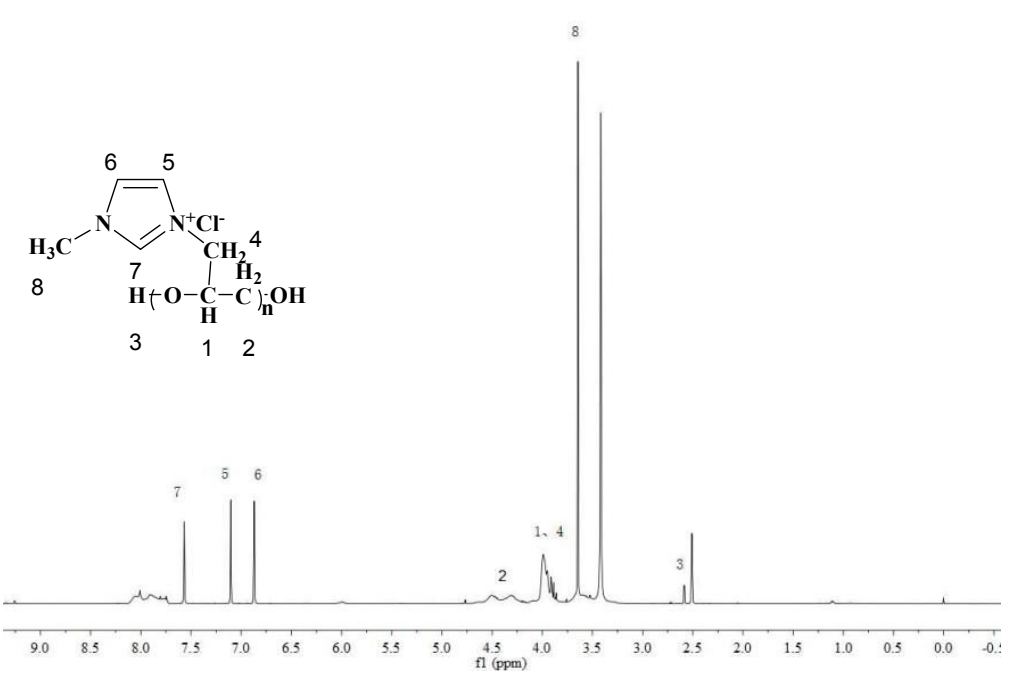

Fig. S6 ${ }^{\mathrm{I}} \mathrm{H}$ NMR spectra of PIL-1 in DMSO-d ${ }_{6}$.

The molecular weight of PECH was 1000. The FT-IR spectra of the PIL-1 revealed the presence of the characteristic peak corresponding to $\mathrm{C}-\mathrm{O}$ bond stretching vibration around $1174 \mathrm{~cm}^{-1}$, it proved that a large number of ether linkages exited in the polymer chains (Fig. S5). A band at 2958 3200 $\mathrm{cm}^{-1}$ appeared in the FT-IR spectrum, which was the characteristic stretching vibration of the $\mathrm{C}-\mathrm{H}$ band. The spectra around $1340 \mathrm{~cm}^{-1}$ and $1130 \mathrm{~cm}^{-1}$ belongs to the $\mathrm{S}=\mathrm{O}$ bond of $\left[\mathrm{NTf}_{2}\right]^{-}$, which proves the exchange between $\mathrm{Cl}^{-}$and $\left(\mathrm{NTf}_{2}\right)^{-}$. From DSC result, PIL were liquid above room temperature with the low glass transition temperature $\left(\mathrm{Tg}<0^{\circ} \mathrm{C}\right)$ (Table. S1).

Table. S1 Tg of PILs from DSC results and $\mathrm{Cl}^{-}$content of PILs from ion chromatography.

\begin{tabular}{ccccc}
\hline PIL & PIL-1 & PIL-2 & PIL-3 & PIL-4 \\
\hline $\operatorname{Tg}\left({ }^{\circ} \mathrm{C}\right)$ & -15.6 & -10.0 & -57.1 & -61.7 \\
$\mathrm{Cl}^{-}$content $(\mathrm{mg} / \mathrm{kg})$ & 35.8 & 24.7 & 21.5 & 0 \\
\hline
\end{tabular}




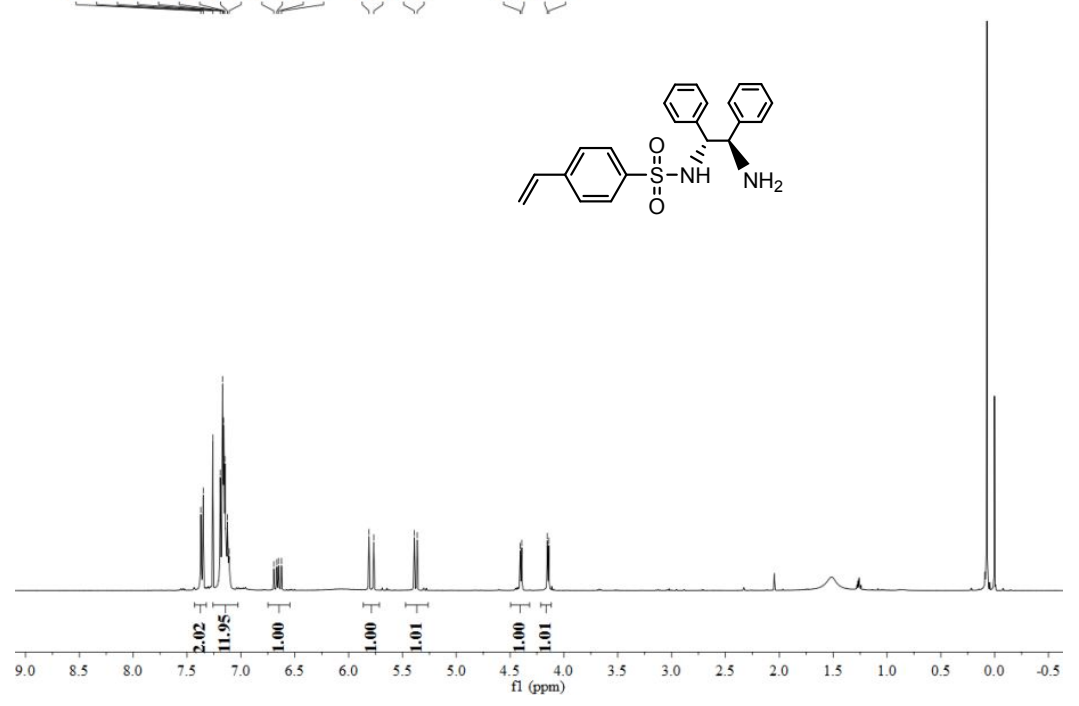

Fig. $\mathrm{S} 7{ }^{1} \mathrm{H}$ NMR of V-TsDPEN in $\mathrm{CDCl}_{3}$.

${ }^{1} \mathrm{H} \mathrm{NMR}\left(400 \mathrm{MHz}, \mathrm{CDCl}_{3}\right) \delta 7.36(\mathrm{~d}, \mathrm{~J}=8.5 \mathrm{~Hz}, 2 \mathrm{H}), 7.26-7.03(\mathrm{~m}, 12 \mathrm{H}), 6.66$ (dd, J = 17.6, 10.9 Hz, 1H), 5.79 (d, J = 17.6 Hz, 1H), 5.38 (d, J = 10.9 Hz, 1H), 4.40 $(\mathrm{d}, \mathrm{J}=5.0 \mathrm{~Hz}, 1 \mathrm{H}), 4.15(\mathrm{~d}, \mathrm{~J}=5.0 \mathrm{~Hz}, 1 \mathrm{H})$.

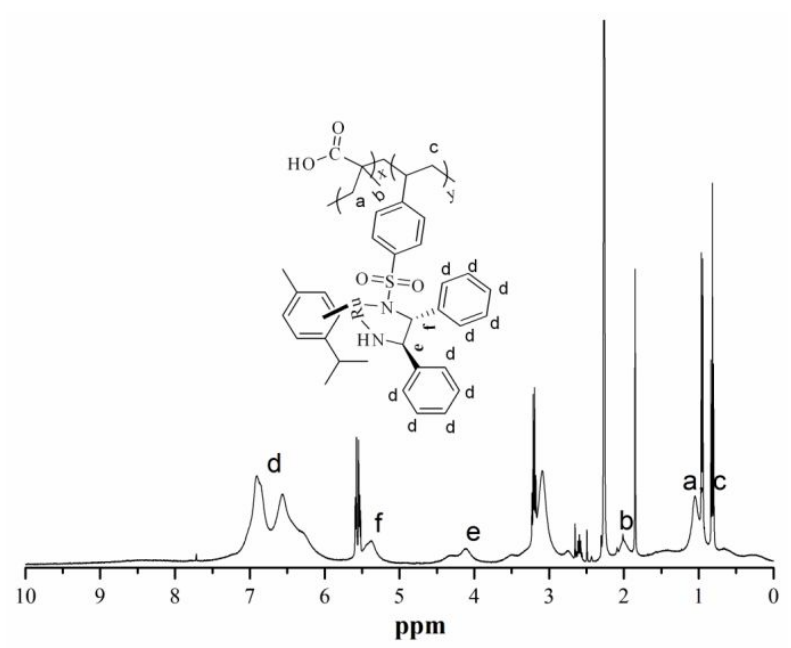

Fig. S8 ${ }^{1} \mathrm{H}$ NMR spectrum of copolymer in DMSO-d $\mathrm{d}_{6}$.

The chiral copolymer was prepared via free radical copolymerization, and its structure was characterized by ${ }^{1} \mathrm{H}-\mathrm{NMR}$ (Fig. S7). The composition of copolymer was determined from the relationship of polymer signals distinct to each component, 
namely the $\delta$ signals of $1.80-2.20$ ppm for PMAA $\left(\mathrm{H}_{\mathrm{b}}\right)$ and $6.20-7.50 \mathrm{ppm}$ for chiral monomers N-styrene V-TsDPEN $\left(\mathrm{H}_{\mathrm{d}}\right)$. These measurements revealed that the molar ratio of MAA to chiral ligand was 0.84 .

The thermal stability of catalyst has a significant impact on the circulation stability of catalyst. Here, we further verified the thermal stability of the catalysts by TGA analysis (Fig. S9). The results showed that the hydrophilic Cat-2 bound more water, resulting in a significant weight loss when heated to $100^{\circ} \mathrm{C}$. Cats-(3-5) showed relatively high thermal stability, and the decomposition temperatures corresponding to the loss of $5 \%$ weight content were $242^{\circ} \mathrm{C}$ for Cat-3, $231^{\circ} \mathrm{C}$ for Cat- 4 and $272^{\circ} \mathrm{C}$ for Cat-5, respectively.

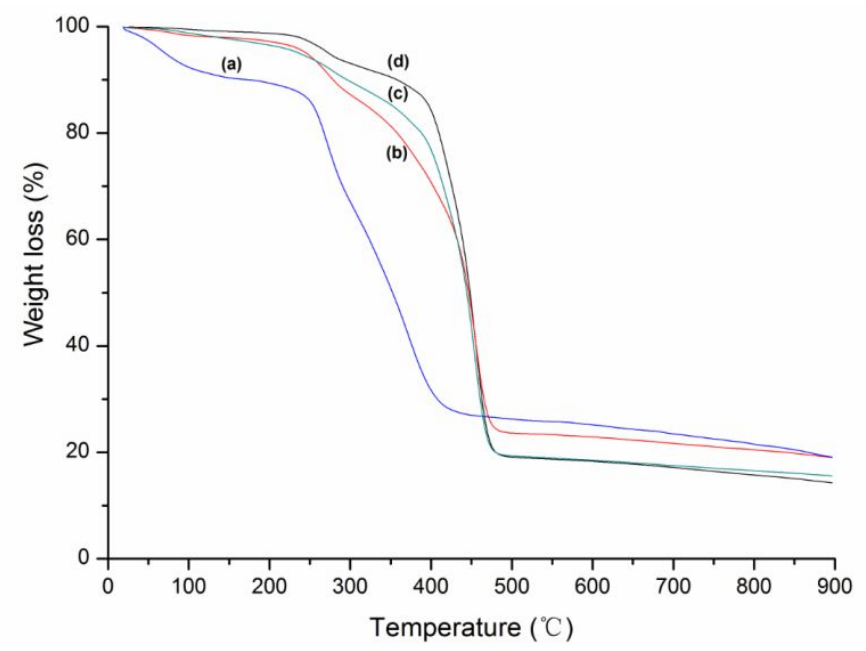

Fig. S9 Thermogravimetric curves of (a) Ru catalyst-1, (b) Ru catalyst-2, (c) Ru catalyst-3, and (d)

$\mathrm{Ru}$ catalyst -4 . Test conditions: in the air, the temperature was raised from room temperature to $900{ }^{\circ} \mathrm{C}$ at the rate of $10^{\circ} \mathrm{C} / \mathrm{min}$.

Table. S2 Elemental analysis results of Ru catalysts. 


\begin{tabular}{ccccc}
\hline Catalysts & $\mathrm{C}$ & $\mathrm{N}$ & $\mathrm{H}$ & $\mathrm{S}$ \\
\hline Ru catalyst-1 & 47.90 & 6.34 & 5.08 & 3.54 \\
& & & & \\
Ru catalyst-2 & 42.15 & 7.64 & 4.64 & 3.15 \\
Ru catalyst-3 & 35.06 & 8.42 & 3.67 & 2.77 \\
Ru catalyst-4 & 45.63 & 7.14 & 4.67 & 1.92 \\
\hline
\end{tabular}

X-ray photoelectron spectroscopy (XPS) was used to further explore the oxidation state and chemical environment of synthesized catalysts, as shown in Fig. S10. The binding energy of $(\operatorname{Ru}(3 \mathrm{~d} 3 / 2)$ and $\mathrm{Ru}(3 \mathrm{~d} 5 / 2)$ for $\mathrm{Ru}$ catalyst-2 were 284.8 $\mathrm{eV}$ and $286.8 \mathrm{eV}$ (Fig. S11). By comparing the XPS spectra of homogeneous catalyst (V-TsDPEN-Ru) and catalyst, we found that they have similar binding energy of Ru, and it further proved that $\mathrm{Ru}$ catalyst has been immobilized on the composite material. $\operatorname{Pd} 3 \mathrm{~d} 5 / 2$ and $\mathrm{Pd} 3 \mathrm{~d} 3 / 2$ spin orbit components of Cat-2 were centred at $338.3 \mathrm{eV}$ and $343.5 \mathrm{eV}$, respectively, indicating that palladium exist in +2 oxidation state in catalyst (Fig. S11). The results were consistent with the small molecule catalyst $\left(\mathrm{Pd}(\mathrm{OAC})_{2}\right)$. From these data, it was further proved that Pd catalyst has been adsorbed on the material. In addition, we found that the peak of $\mathrm{Ru}$ on the catalyst surface was not obvious, which may be the reason that $\mathrm{Pd}(\mathrm{OAC})_{2}$ was added to the catalyst surface to cover up $\mathrm{Ru}$ inside the catalyst. In addition, the abundance of $\mathrm{F}$ observed in Cat-2, Cat-3 and Cat-4 verified the presence of $\left[\mathrm{NTf}_{2}\right]^{-}$in the catalysts. Moreover, the contents of $\mathrm{Ru}$ and $\mathrm{Pd}$ in the materials were analyzed by ICP. The results were shown in Table S3. The EDS results provide evidence of S, N, Ru and Pd elements in all four supported catalysts (Table.S4), confirming the successful preparation of chiral Ru-Pd catalysts. 


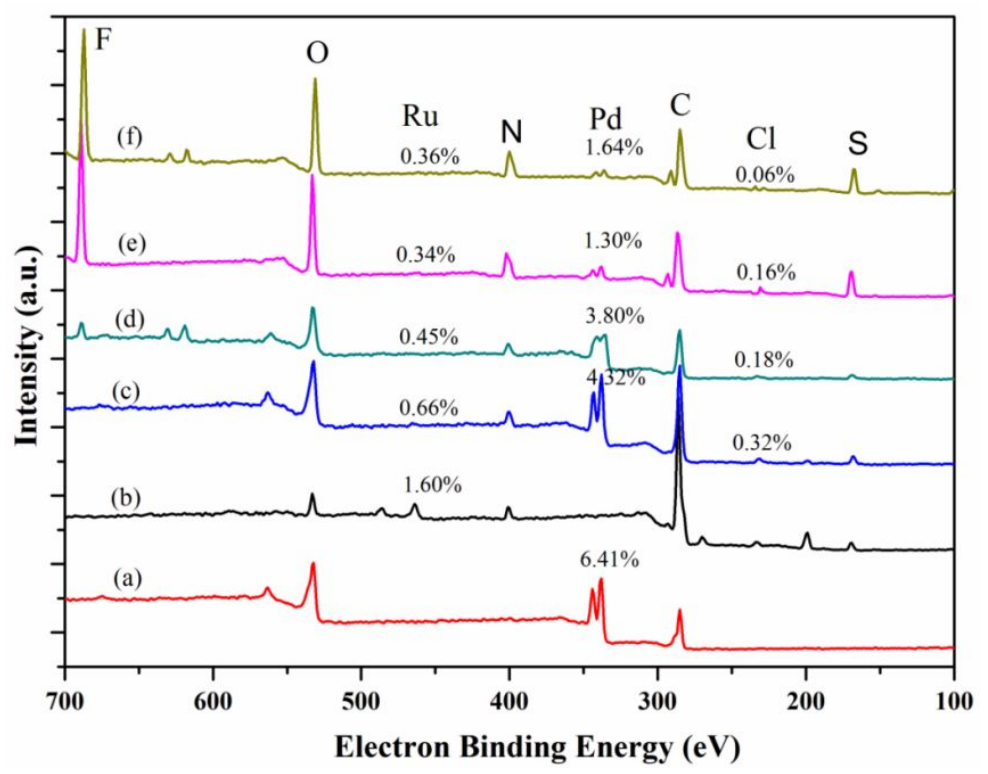

Fig. S10 XPS spectra of (a) Pd(OAC) 2, (b) Ru-TsDPEN, (c) Cat-1, (d) Cat-2, (e) Cat-3 and (f) Cat-4.
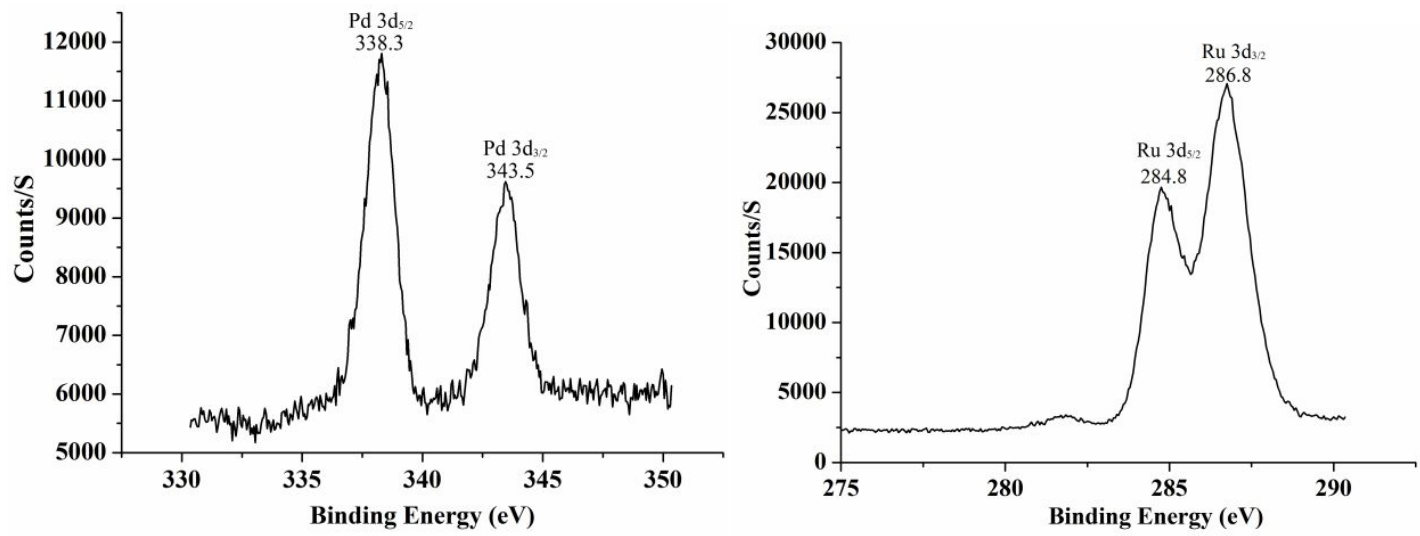

Fig. S11 XPS spectra of (left) Pd 3d in Ru-Pd Cat-2, and (right) Ru 3d in Ru catalyst-2.

Table. S3 Proportion of catalyst and its Ru and Pd loading

\begin{tabular}{lcccc}
\hline Catalysts & $\begin{array}{c}\text { PIL/copolymer (mol) } \\
\text { (theroy) }\end{array}$ & $\begin{array}{c}\text { PIL/copolymer (mol ratio) } \\
\text { (elemental analysis) }\end{array}$ & $\begin{array}{c}\text { Ru loading } \\
\text { (wt.\%) } \\
(\text { ICP) }\end{array}$ & $\begin{array}{c}\text { Pd loading } \\
\text { (wt.\%) }\end{array}$ \\
\hline Cat-1 & $2 / 1$ & $1.21: 1^{\mathrm{a}}$ & 4.21 & 1.82 \\
Cat-2 & $2 / 1$ & $1.14: 1^{\mathrm{a}}$ & 5.61 & 1.47 \\
Cat-3 & $2 / 1$ & $1.42: 1^{\mathrm{b}}$ & 4.82 & 1.32 \\
\hline
\end{tabular}




\begin{tabular}{lccc}
\hline Cat-4 & $2 / 1$ & $1.13: 1^{\mathrm{a}}$ & 5.21 \\
Cat-2 ${ }^{\mathrm{b}}$ & & 5.42 & 1.44 \\
\hline
\end{tabular}

${ }^{\mathrm{a} C a l c u l a t i o n}$ of $\mathrm{N}$ molar ratio of PIL and copolymer based on elemental analysis of catalysts in table S2, N molar contents of chiral copolymers were calculated acccording to the Ru content of catalysts. bafter 10 cycles for Cat- 2 .

Table. S4 EDS analyses results (wt.\%) on catalyst surfaces from SEM.

\begin{tabular}{cccccccc}
\hline Catalyst & $\mathrm{C}$ & $\mathrm{N}$ & $\mathrm{Cl}$ & $\mathrm{F}$ & $\mathrm{S}$ & $\mathrm{Ru}$ & $\mathrm{Pd}$ \\
$\mathrm{S}$ & & & & & & & \\
\hline & & & & & & & \\
\hline Cat-1 & $27.83 \pm 4.0$ & $7.64 \pm 3.2$ & $1.58 \pm 0.4$ & 0 & $14.21 \pm 1.5$ & $14.76 \pm 3.1$ & $2.05 \pm 1.3$ \\
& 3 & 6 & 2 & & 0 & 0 & 2 \\
Cat-2 & $29.98 \pm 4.2$ & $3.91 \pm 3.5$ & $0.96 \pm 0.7$ & $10.55 \pm 2.1$ & $21.73 \pm 2.2$ & $13.64 \pm 3.0$ & $3.14 \pm 2.1$ \\
& 4 & 5 & 0 & 9 & 1 & 2 & 3 \\
Cat-3 & $25.90 \pm 3.8$ & $7.01 \pm 2.7$ & $0.69 \pm 0.1$ & $11.50 \pm 2.2$ & $25.29 \pm 1.9$ & $17.71 \pm 3.0$ & $1.66 \pm 1.1$ \\
& 4 & 6 & 1 & 3 & 5 & 6 & 2 \\
Cat-4 & $26.09 \pm 3.9$ & $5.06 \pm 3.1$ & 0 & $13.66 \pm 2.4$ & $33.06 \pm 2.0$ & $13.36 \pm 3.2$ & $1.85 \pm 0.7$ \\
& 1 & 2 & & 5 & 4 & 1 & 7 \\
\hline
\end{tabular}

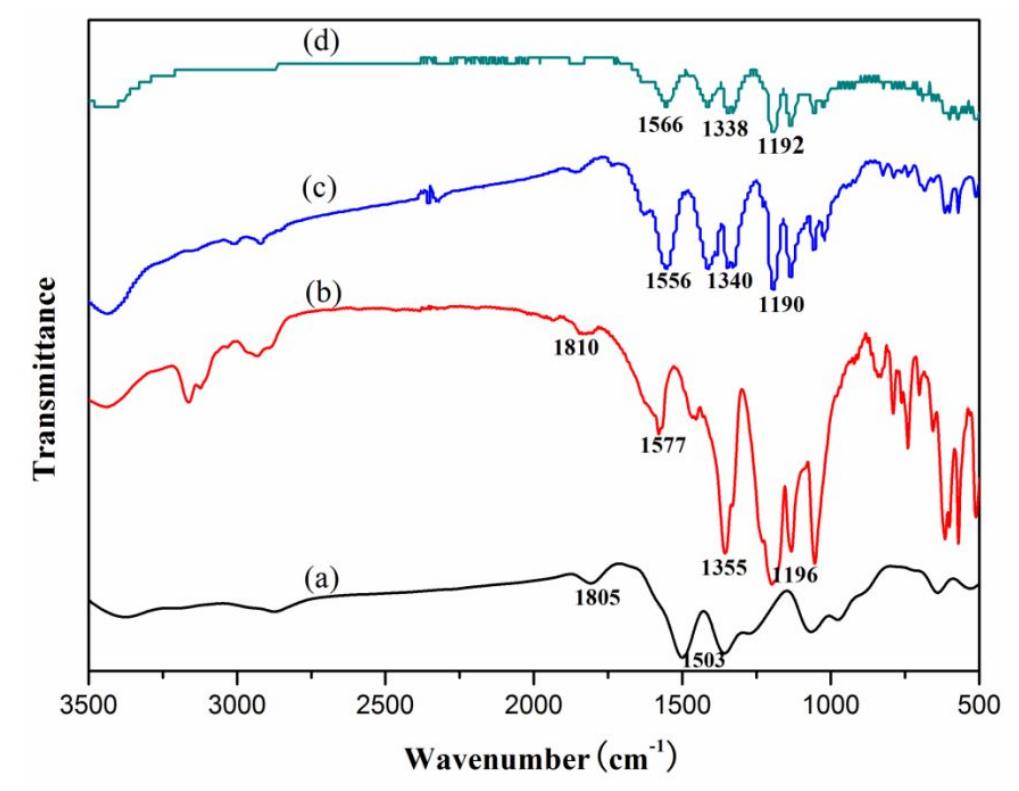

Fig. S12 FTIR spectra of (a) Cat-1, (b) Cat-2, (c) Cat-3, and (d) Cat-4.

Fig. S12 depicts the FTIR spectra of the catalysts, which are marked by broad 
absorption peaks around $3383-3500 \mathrm{~cm}^{-1}$, which in catalysts are generally attributed to infrared absorption caused by water content and active hydrogen. The peaks at about $2900 \mathrm{~cm}^{-1}$ denote the vibration of alkyl chains in the ionic liquids. The peaks in the range of $1810-1850 \mathrm{~cm}^{-1}$ correspond to the infrared absorption of the $\mathrm{C}=\mathrm{C}$ double bond in the catalysts. Compared to those of Cat-1, the infrared absorption peaks of $\mathrm{S}=\mathrm{O}$ and $\mathrm{C}-\mathrm{F}$ in $\left[\mathrm{NTf}_{2}\right]^{-}$at $1132-1135 \mathrm{~cm}^{-1}$ and $1332-1348 \mathrm{~cm}^{-1}$ are more prominent for Cat-2, Cat-3 and Cat-4, indicating that different PILs are effectively immobilized on the catalyst. Overall, from these results it can be determined that the catalysts were prepared successfully.

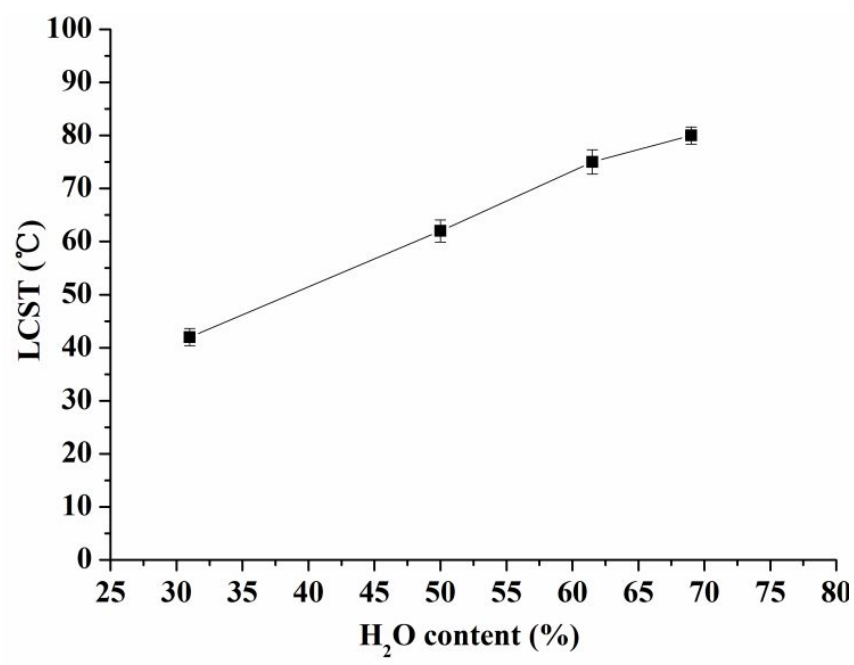

Fig. S13 The phase transition temperature of Cat-2 in mixtures of $\mathrm{H}_{2} \mathrm{O} / \mathrm{iPrOH}$ with different volume fractions of water.

\section{Catalysts used in asymmetric transfer hydrogenation and coupling reactions}

The catalyst $(0.1 \mathrm{mmol} \% \mathrm{Ru}$, different $\mathrm{Pd}$ content $), 1 \mathrm{mmol}$ of acetophenone iodide, $1.1 \mathrm{mmol}$ of phenylboronic acid, $1.0 \mathrm{mmol}$ of $\mathrm{HCOO}_{2} \mathrm{Na}, 0.3 \mathrm{mmol}$ of $\mathrm{Cs}_{2} \mathrm{CO}_{3}$ and $4 \mathrm{~mL}$ of $\mathrm{H}_{2} \mathrm{O} / \mathrm{iPrOH}$ mixed solvent were added into the test tube. The 
reaction was carried out at $60{ }^{\circ} \mathrm{C}$ for $3 \mathrm{~h}$ or $6 \mathrm{~min}$, and then cooled to $25^{\circ} \mathrm{C}$ for $10 \mathrm{~h}$ (TLC was used to monitor the reaction until the end of the reaction). After the reaction, the catalyst was recovered by centrifugation, washed and dried repeatedly with ethanol, and then recycled for the next time. The reaction liquid was extracted by ethyl acetate, and the organic mixture was separated by column chromatography to obtain the pure product.

To assess the stability of the catalyst and the activity of the catalytic reaction, we subjected Cat-2 to ten cycles of repeated use. As shown in Fig. S16, 4-iodoacetophenone and phenylboronic acid served as substrates to carry out repeated experiments under the optimum conditions, with simple centrifugation and washing.

Table. S5 Coupling and hydrogen transfer reactions of Cat-3 and Cat-4 at different temperatures ${ }^{\mathrm{a}}$.

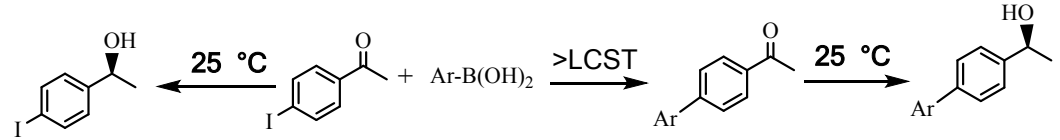

(C)
(B)
(D)

\begin{tabular}{|c|c|c|c|c|c|c|}
\hline Catalysts & Temperature $\left({ }^{\circ} \mathrm{C}\right)$ & Time (h) & byield \% & $\begin{array}{c}\text { Yield } \\
\%\end{array}$ & $\begin{array}{c}\text { Yield } \\
\%\end{array}$ & bee $(\%)$ \\
\hline
\end{tabular}

(B)

\begin{tabular}{|c|c|c|c|c|c|c|}
\hline & & & & (C) & (D) & \\
\hline \multirow{2}{*}{ Cat-3 } & First 80 & 3 & 99.9 & 0 & nd & \\
\hline & Then 25 & 10 & nd & 0 & 99.9 & 92.1 \\
\hline \multirow[t]{2}{*}{ Cat-4 } & First 90 & 3 & 99.9 & $n d^{c}$ & nd & \\
\hline & Then 25 & 10 & nd & nd & 99.9 & 94.2 \\
\hline
\end{tabular}

aReaction conditions: $0.1 \%$ mmol of $\mathrm{Ru}$ (based on ICP analysis), $\mathrm{Cs}_{2} \mathrm{CO}_{3}(0.12 \mathrm{mmol}), \mathrm{HCO}_{2} \mathrm{Na}$ $(1.0 \mathrm{mmol})$, iodoacetophenones $(0.10 \mathrm{mmol})$, arylboronic acids $(0.12 \mathrm{mmol})$, and $2.0 \mathrm{~mL}$ of $\mathrm{H}_{2} \mathrm{O} / \mathrm{PPrOH}(\mathrm{v} / \mathrm{v}=1: 1)$ were added sequentially to a $10.0 \mathrm{~mL}$ round-bottomed flask. ${ }^{b}$ Yields were determined by ${ }^{1} \mathrm{H}$ NMR and ee values were determined using chiral HPLC analysis. ${ }^{\mathrm{c} n d}=\mathrm{not}$ detected. 


\section{5. ${ }^{1} \mathrm{H}$ NMR of the chiral product}

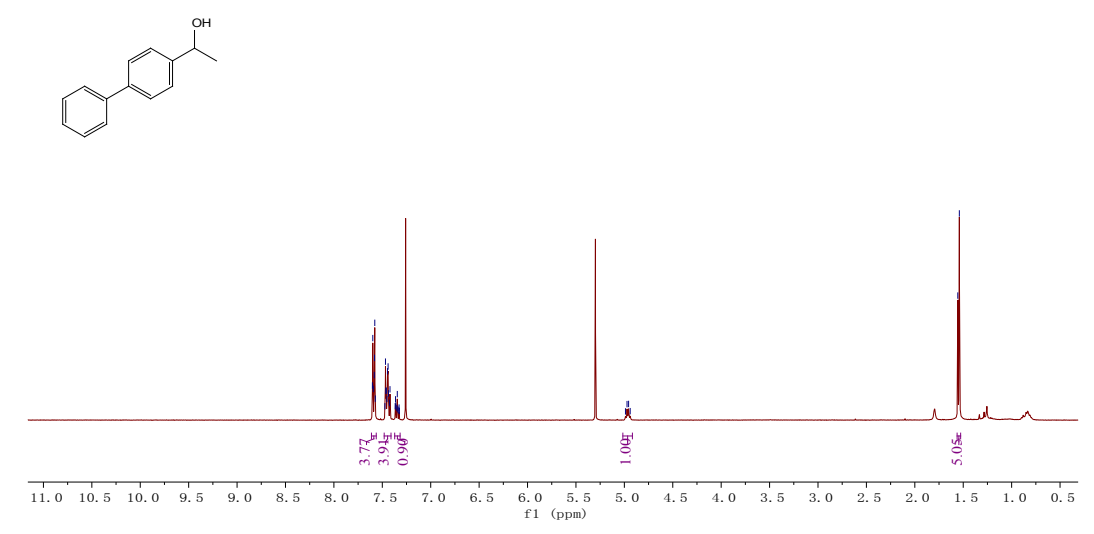

Fig. S14 ${ }^{1} \mathrm{H}$ NMR of 1-([1,1'-biphenyl]-4-yl)ethan-1-ol in $\mathrm{CDCl}_{3}$.

${ }^{1} \mathrm{H}$ NMR (400 MHz, Chloroform- $d$ ) $\delta 7.61-7.56(\mathrm{~m}, 4 \mathrm{H}), 7.48-7.41(\mathrm{~m}, 4 \mathrm{H}), 7.37$

$-7.32(\mathrm{~m}, 1 \mathrm{H}), 4.96(\mathrm{q}, J=6.5 \mathrm{~Hz}, 1 \mathrm{H}), 1.55(\mathrm{~d}, J=6.4 \mathrm{~Hz}, 3 \mathrm{H})$.

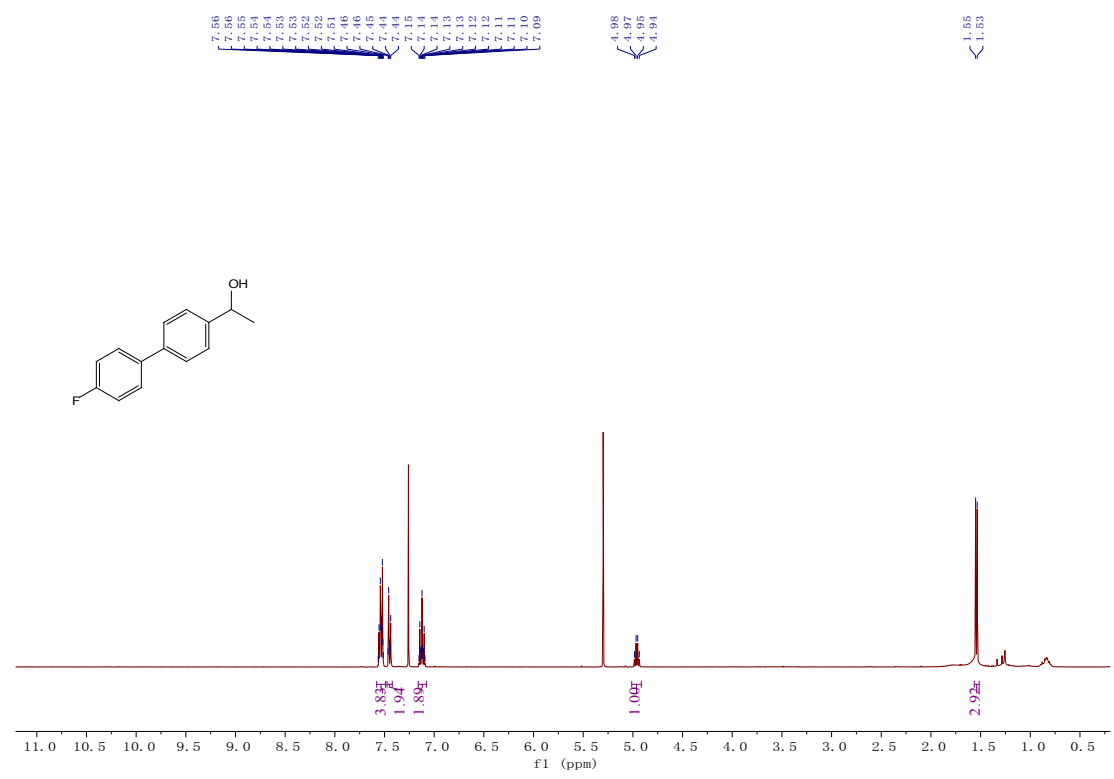

Fig. S15 ${ }^{1} \mathrm{H}$ NMR of 1-(4'-fluoro-[1,1'-biphenyl]-4-yl)ethan-1-ol in $\mathrm{CDCl}_{3}$.

${ }^{1} \mathrm{H}$ NMR (400 MHz, Chloroform- $d$ ) $\delta 7.58-7.49(\mathrm{~m}, 4 \mathrm{H}), 7.47-7.42(\mathrm{~m}, 2 \mathrm{H}), 7.16$

$-7.08(\mathrm{~m}, 2 \mathrm{H}), 4.96(\mathrm{q}, J=6.5 \mathrm{~Hz}, 1 \mathrm{H}), 1.54(\mathrm{~d}, J=6.5 \mathrm{~Hz}, 3 \mathrm{H})$. 


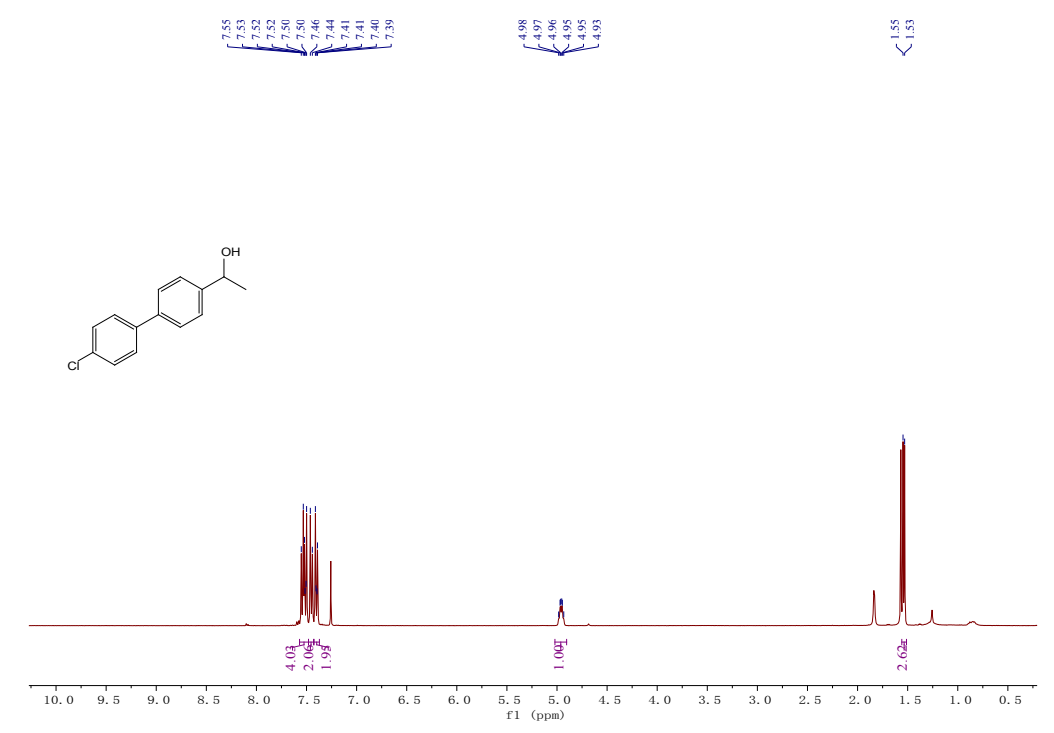

Fig. S16 ${ }^{1} \mathrm{H}$ NMR of 1-(4'-chloro-[1,1'-biphenyl]-4-yl)ethan-1-ol in $\mathrm{CDCl}_{3}$.

${ }^{1} \mathrm{H}$ NMR (400 MHz, Chloroform- $d$ ) $\delta 7.53(\mathrm{dd}, J=12.9,8.2 \mathrm{~Hz}, 4 \mathrm{H}), 7.45$ (d, $J=8.1$ $\mathrm{Hz}, 2 \mathrm{H}), 7.40$ (d, $J=8.4 \mathrm{~Hz}, 2 \mathrm{H}), 4.95$ (dt, $J=8.1,4.0 \mathrm{~Hz}, 1 \mathrm{H}), 1.54$ (d, $J=6.4 \mathrm{~Hz}$, $3 \mathrm{H})$.
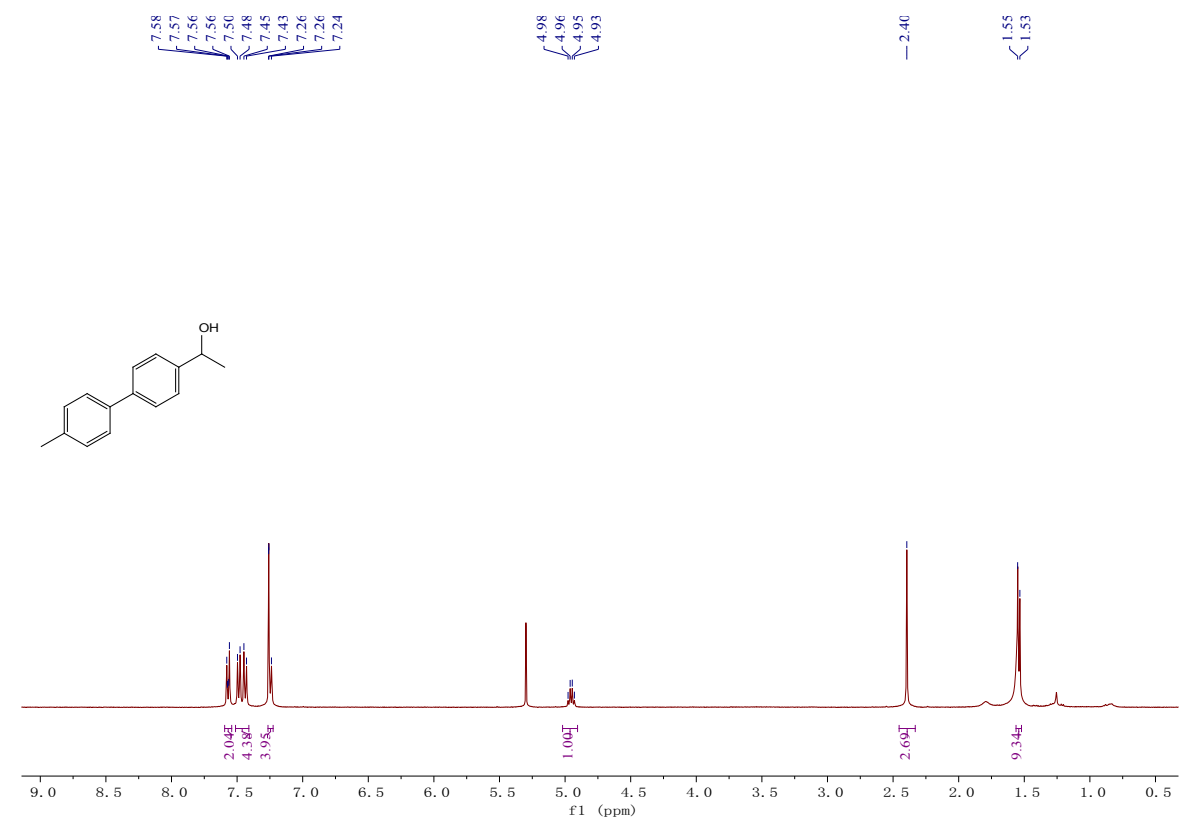

Fig. S17 ${ }^{1} \mathrm{H}$ NMR of 1-(4'-methyl-[1,1'-biphenyl]-4-yl)ethan-1-ol in $\mathrm{CDCl}_{3}$

${ }^{1} \mathrm{H}$ NMR (400 MHz, Chloroform- $d$ ) $\delta 7.57$ (d, $\left.J=8.1 \mathrm{~Hz}, 2 \mathrm{H}\right), 7.46$ (dd, $J=19.6,7.9$ $\mathrm{Hz}, 4 \mathrm{H}), 7.26-7.23(\mathrm{~m}, 2 \mathrm{H}), 4.95$ (q, $J=6.4 \mathrm{~Hz}, 1 \mathrm{H}), 2.40$ (s, 3H), 1.54 (d, $J=6.8$ $\mathrm{Hz}, 3 \mathrm{H})$. 


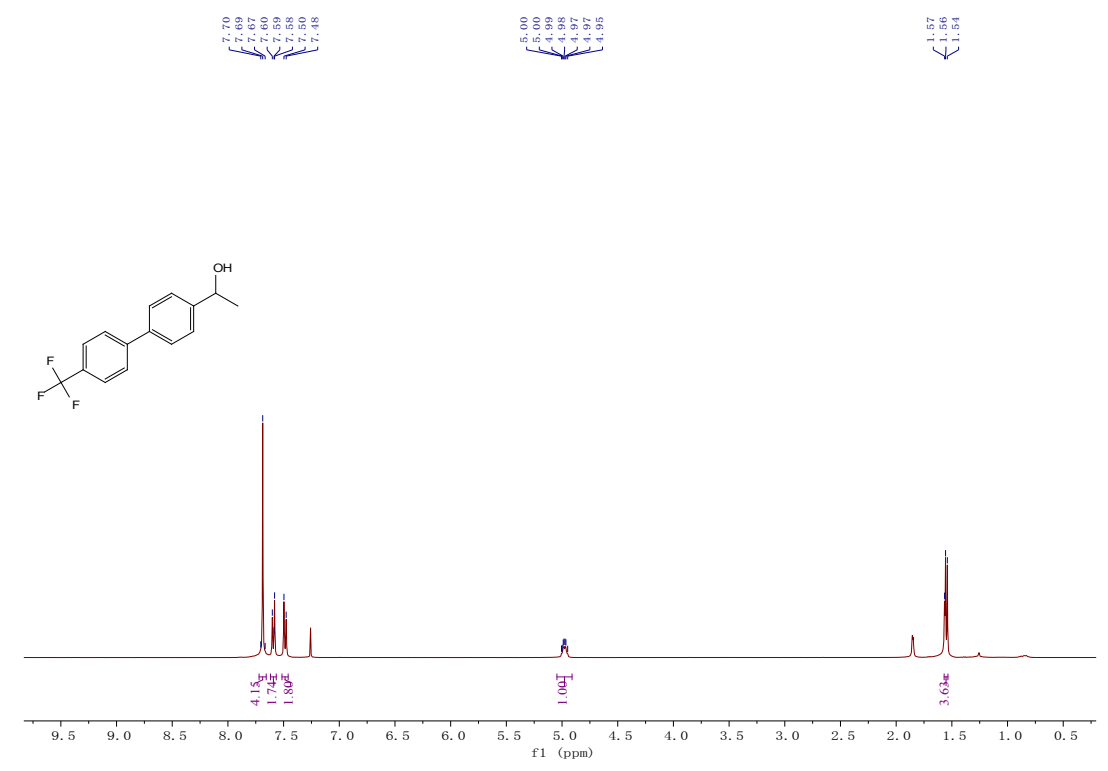

Fig. S18 ${ }^{1} \mathrm{H}$ NMR of 1-(4'-(trifluoromethyl)-[1,1'-biphenyl]-4-yl)ethan-1-ol in $\mathrm{CDCl}_{3}$.

${ }^{1} \mathrm{H}$ NMR (400 MHz, Chloroform-d) $\delta 7.69$ (s, 4H), 7.59 (d, $\left.J=8.1 \mathrm{~Hz}, 2 \mathrm{H}\right), 7.49$ (d, $J$ $=8.0 \mathrm{~Hz}, 2 \mathrm{H}), 4.98(\mathrm{tt}, J=9.4,4.5 \mathrm{~Hz}, 1 \mathrm{H}), 1.57-1.54(\mathrm{~m}, 3 \mathrm{H})$.
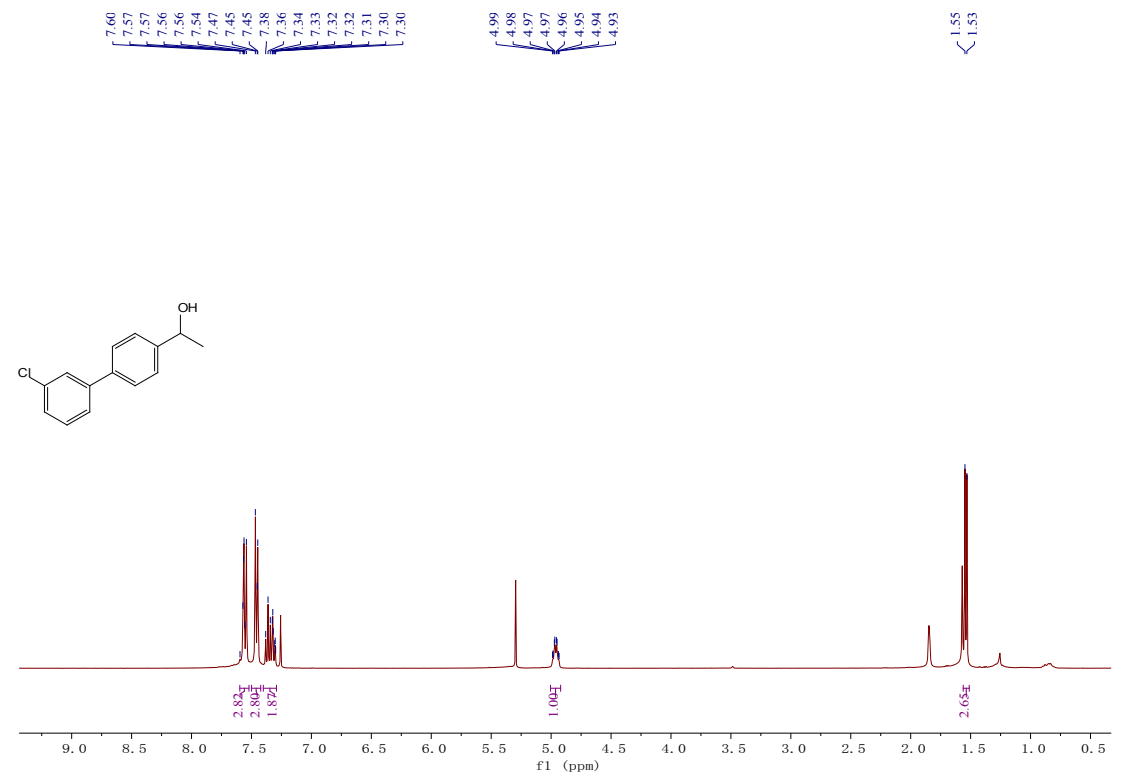

Fig. S19 'H NMR of 1-(3'-chloro-[1,1'-biphenyl]-4-yl)ethan-1-ol in $\mathrm{CDCl}_{3}$.

${ }^{1} \mathrm{H}$ NMR (400 MHz, Chloroform- $d$ ) $\delta 7.60-7.52(\mathrm{~m}, 3 \mathrm{H}), 7.46(\mathrm{~d}, J=8.0 \mathrm{~Hz}, 3 \mathrm{H})$, $7.40-7.29$ (m, 2H), 4.96 (h, $J=5.4,4.7 \mathrm{~Hz}, 1 \mathrm{H}), 1.54$ (d, $J=6.4 \mathrm{~Hz}, 3 \mathrm{H})$. 

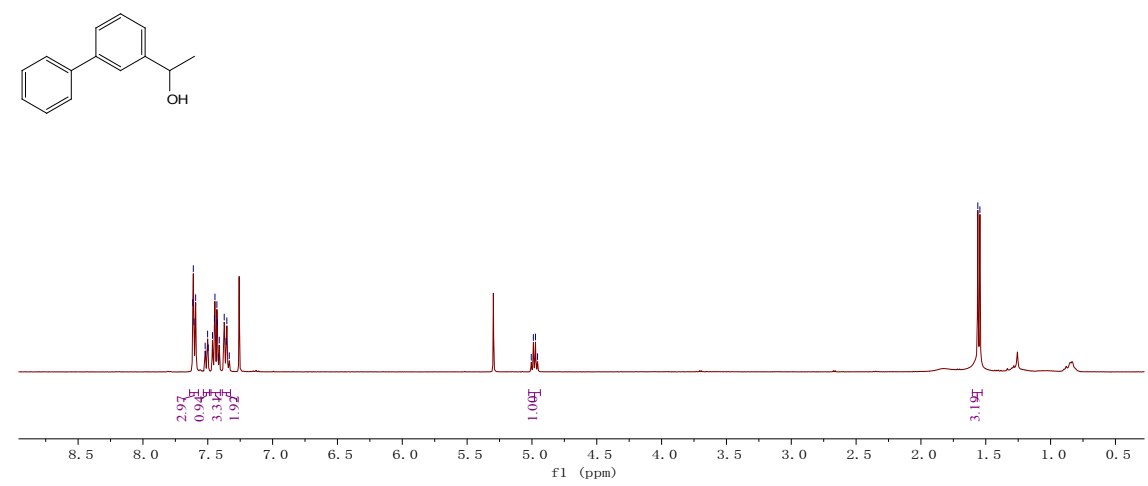

Fig. S20 ${ }^{1} \mathrm{H}$ NMR of 1-([1,1'-biphenyl]-3-yl)ethan-1-ol in $\mathrm{CDCl}_{3}$.

${ }^{1} \mathrm{H}$ NMR (400 MHz, Chloroform- $d$ ) $\delta 7.64-7.57(\mathrm{~m}, 3 \mathrm{H}), 7.51(\mathrm{~d}, J=7.5 \mathrm{~Hz}, 1 \mathrm{H})$, $7.44(\mathrm{td}, J=7.5,5.8 \mathrm{~Hz}, 3 \mathrm{H}), 7.35(\mathrm{dd}, J=8.9,6.7 \mathrm{~Hz}, 2 \mathrm{H}), 4.98(\mathrm{q}, J=6.4 \mathrm{~Hz}, 1 \mathrm{H})$, $1.55(\mathrm{~d}, J=6.5 \mathrm{~Hz}, 3 \mathrm{H})$.
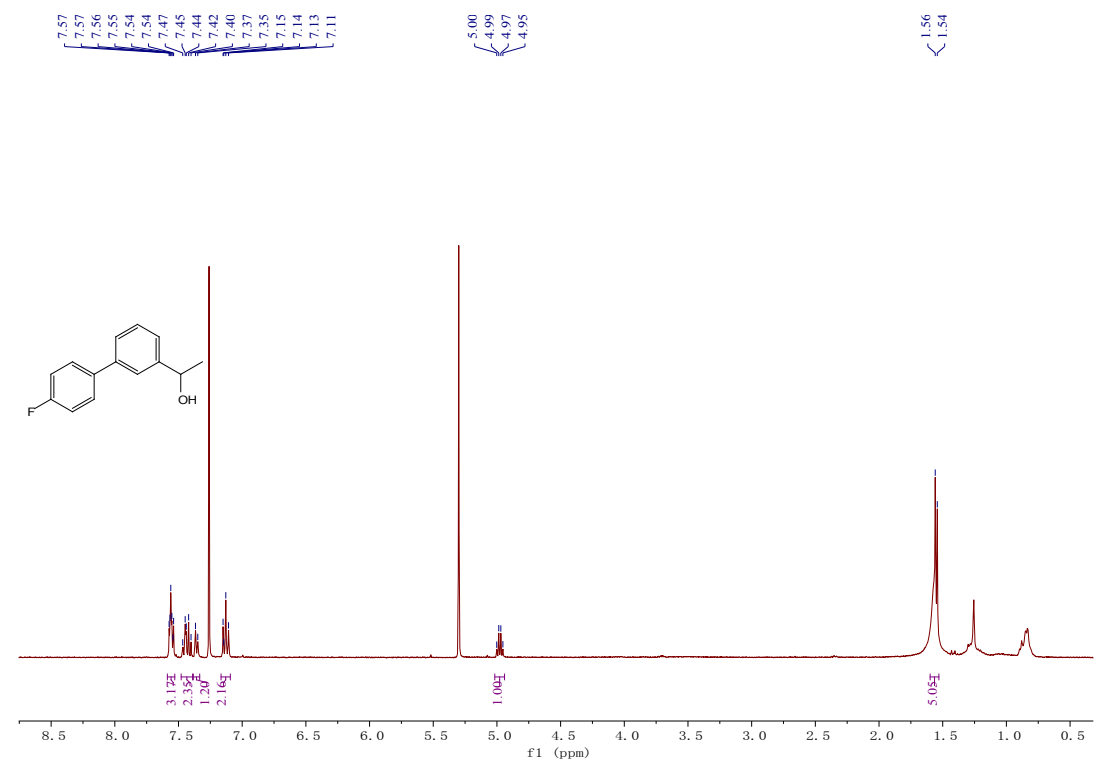

Fig. S21 ${ }^{1} \mathrm{H}$ NMR of 1-(4'-fluoro-[1,1'-biphenyl]-3-yl)ethan-1-ol in $\mathrm{CDCl}_{3}$.

${ }^{1} \mathrm{H}$ NMR (400 MHz, Chloroform- $d$ ) $\delta 7.56(\mathrm{td}, J=5.4,2.4 \mathrm{~Hz}, 3 \mathrm{H}), 7.48-7.39(\mathrm{~m}$, 2H), $7.36(\mathrm{~d}, J=7.2 \mathrm{~Hz}, 1 \mathrm{H}), 7.13(\mathrm{t}, J=8.6 \mathrm{~Hz}, 2 \mathrm{H}), 4.98$ (q, $J=6.5 \mathrm{~Hz}, 1 \mathrm{H}), 1.55$ (d, $J=6.5 \mathrm{~Hz}, 3 \mathrm{H})$. 


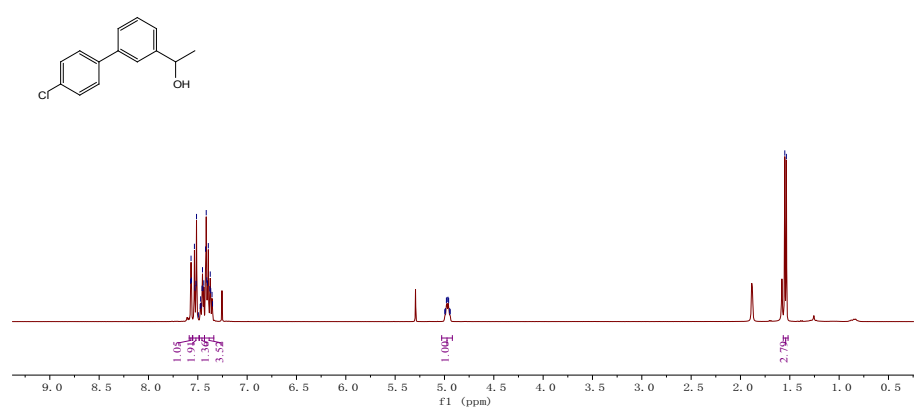

Fig. S22 ${ }^{1} \mathrm{H}$ NMR of 1-(4'-chloro-[1,1'-biphenyl]-3-yl)ethan-1-ol in $\mathrm{CDCl}_{3}$.

${ }^{1} \mathrm{H}$ NMR (400 MHz, Chloroform- $d$ ) $\delta 7.57$ (d, $\left.J=1.8 \mathrm{~Hz}, 1 \mathrm{H}\right), 7.55-7.49(\mathrm{~m}, 2 \mathrm{H})$, $7.46(\mathrm{dd}, J=7.3,5.5 \mathrm{~Hz}, 1 \mathrm{H}), 7.43-7.34(\mathrm{~m}, 4 \mathrm{H}), 4.97$ (qd, $J=6.5,2.3 \mathrm{~Hz}, 1 \mathrm{H})$, $1.54(\mathrm{~d}, J=6.4 \mathrm{~Hz}, 3 \mathrm{H})$.

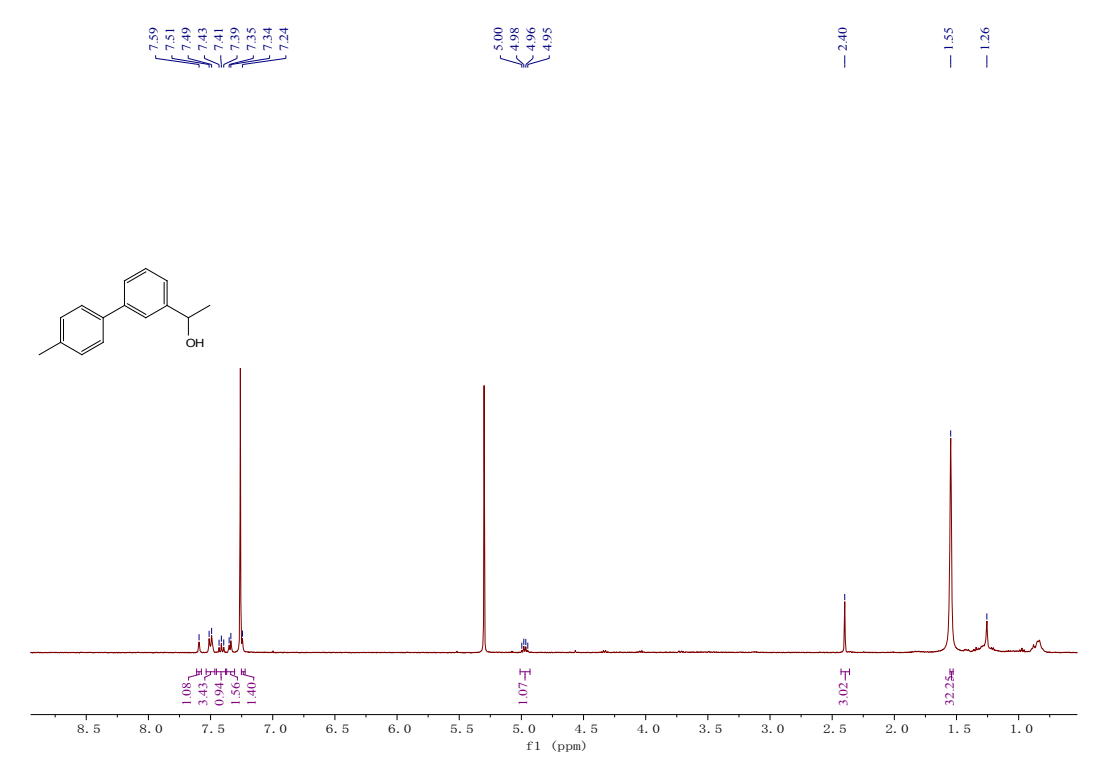

Fig. S23 ${ }^{1} \mathrm{H}$ NMR of 1-(4'-methyl-[1,1'-biphenyl]-3-yl)ethan-1-ol in $\mathrm{CDCl}_{3}$.

${ }^{1} \mathrm{H}$ NMR (400 MHz, Chloroform- $d$ ) $\delta 7.59$ (s, 1H), 7.50 (d, $\left.J=8.0 \mathrm{~Hz}, 3 \mathrm{H}\right), 7.41(\mathrm{t}, J$ $=7.6 \mathrm{~Hz}, 1 \mathrm{H}), 7.34(\mathrm{~d}, J=5.5 \mathrm{~Hz}, 2 \mathrm{H}), 7.24(\mathrm{~s}, 1 \mathrm{H}), 4.97(\mathrm{q}, J=6.4 \mathrm{~Hz}, 1 \mathrm{H}), 2.40(\mathrm{~s}$, $3 \mathrm{H}), 1.55$ (s, 3H). 


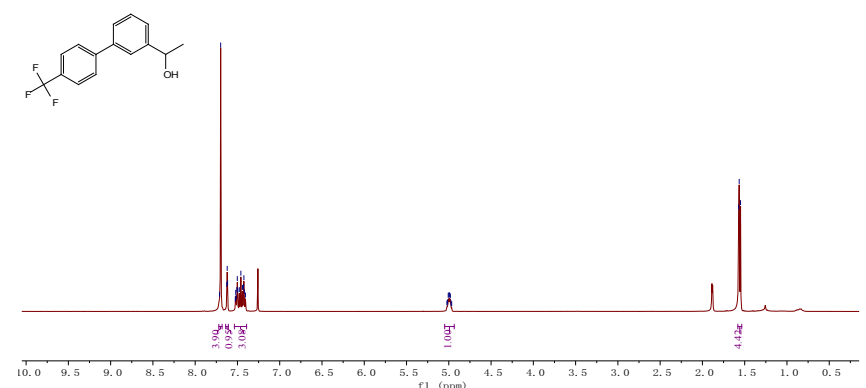

Fig. S24 ${ }^{1} \mathrm{H}$ NMR of 1-(4'-(trifluoromethyl)-[1,1'-biphenyl]-3-yl)ethan-1-ol in $\mathrm{CDCl}_{3}$.

${ }^{1} \mathrm{H}$ NMR (400 MHz, Chloroform- $d$ ) $\delta 7.70$ (s, 4H), 7.62 (d, $\left.J=1.8 \mathrm{~Hz}, 1 \mathrm{H}\right), 7.54-$ $7.39(\mathrm{~m}, 3 \mathrm{H}), 4.99(\mathrm{qd}, J=6.4,3.1 \mathrm{~Hz}, 1 \mathrm{H}), 1.58-1.53(\mathrm{~m}, 3 \mathrm{H})$.

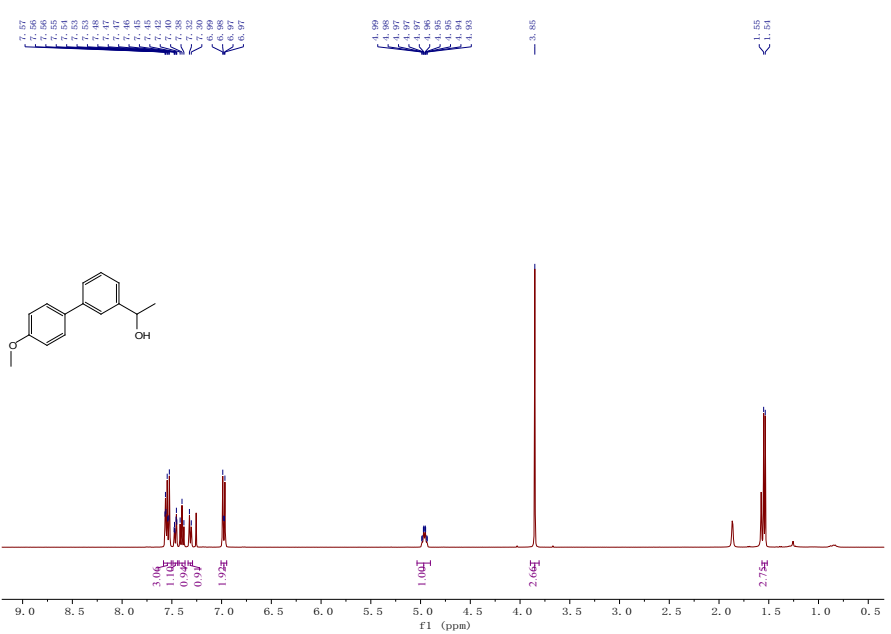

Fig. S25 ${ }^{1} \mathrm{H}$ NMR of 1-(4'-methoxy-[1,1'-biphenyl]-3-yl)ethan-1-ol in $\mathrm{CDCl}_{3}$.

${ }^{1} \mathrm{H}$ NMR (400 MHz, Chloroform- $d$ ) $\delta 7.58-7.51(\mathrm{~m}, 3 \mathrm{H}), 7.46(\mathrm{dt}, J=7.6,1.5 \mathrm{~Hz}$, $1 \mathrm{H}), 7.40(\mathrm{t}, J=7.6 \mathrm{~Hz}, 1 \mathrm{H}), 7.31(\mathrm{~d}, J=7.5 \mathrm{~Hz}, 1 \mathrm{H}), 7.01-6.95(\mathrm{~m}, 2 \mathrm{H}), 4.96(\mathrm{dh}$, $J=7.9,2.0 \mathrm{~Hz}, 1 \mathrm{H}), 3.85(\mathrm{~s}, 3 \mathrm{H}), 1.54(\mathrm{~d}, J=6.4 \mathrm{~Hz}, 3 \mathrm{H})$. 


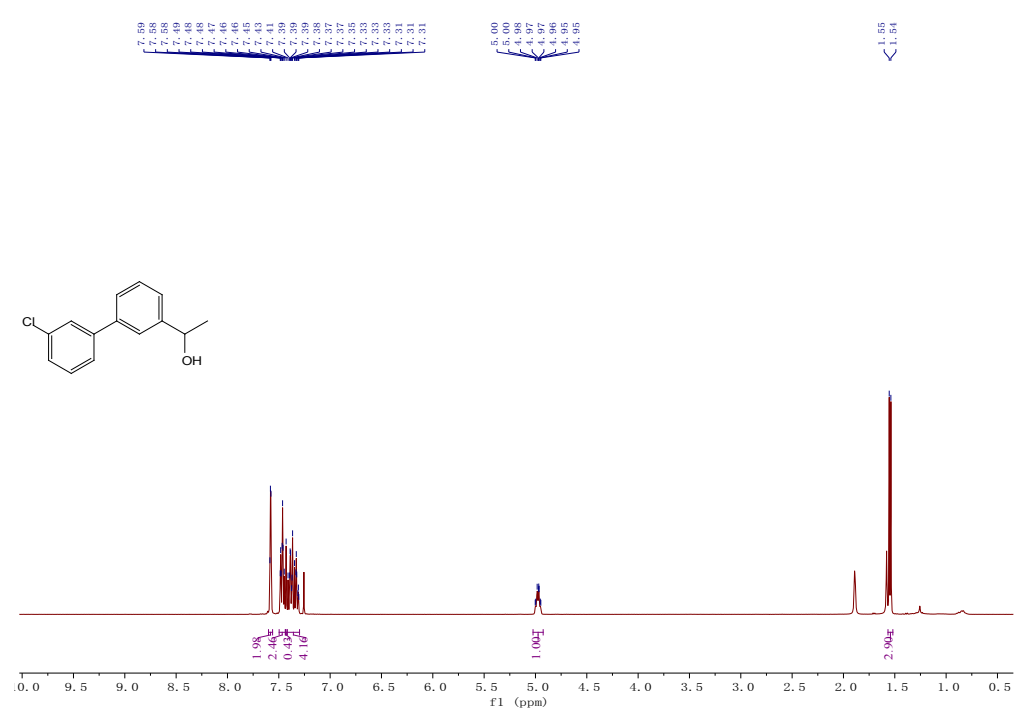

Fig. S26 ${ }^{1} \mathrm{H}$ NMR of 1-(3'-chloro-[1,1'-biphenyl]-3-yl)ethan-1-ol in $\mathrm{CDCl}_{3}$.

${ }^{1} \mathrm{H}$ NMR (400 MHz, Chloroform- $d$ ) $\delta 7.58(\mathrm{~d}, J=2.0 \mathrm{~Hz}, 2 \mathrm{H}), 7.50-7.44(\mathrm{~m}, 2 \mathrm{H})$, $7.42-7.30(\mathrm{~m}, 4 \mathrm{H}), 5.02-4.92(\mathrm{~m}, 1 \mathrm{H}), 1.55(\mathrm{~d}, J=6.4 \mathrm{~Hz}, 3 \mathrm{H})$.

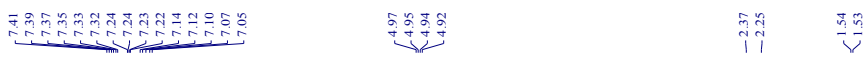
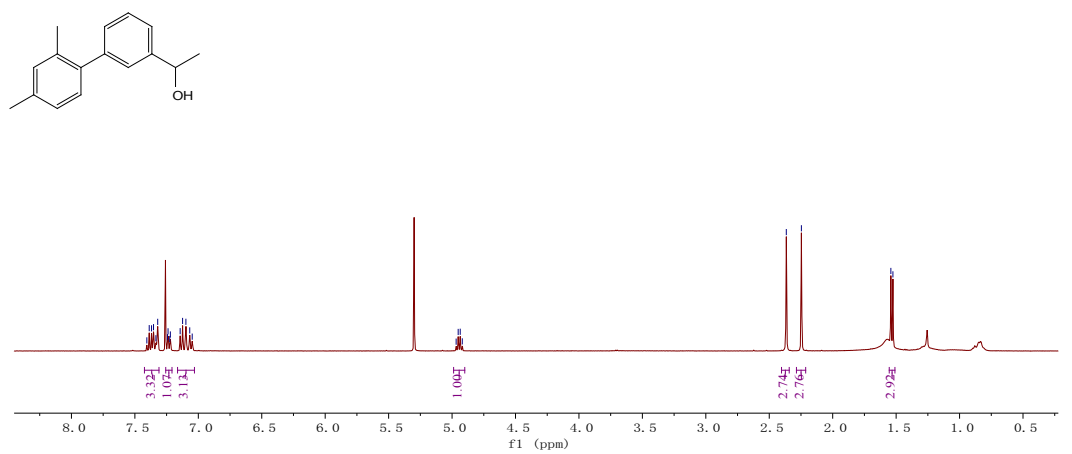

Fig. S27 ${ }^{1} \mathrm{H}$ NMR of 1-(2'4'-dimethyl-[1,1'-biphenyl]-3-yl)ethan-1-ol in $\mathrm{CDCl}_{3}$.

${ }^{1} \mathrm{H}$ NMR (400 MHz, Chloroform- $d$ ) $\delta 7.36(\mathrm{td}, J=14.0,13.2,6.6 \mathrm{~Hz}, 3 \mathrm{H}), 7.23(\mathrm{dd}, J$ $=7.2,1.9 \mathrm{~Hz}, 1 \mathrm{H}), 7.16-7.03(\mathrm{~m}, 3 \mathrm{H}), 4.94(\mathrm{q}, J=6.5 \mathrm{~Hz}, 1 \mathrm{H}), 2.37(\mathrm{~s}, 3 \mathrm{H}), 2.25(\mathrm{~s}$, $3 \mathrm{H}), 1.53(\mathrm{~d}, J=6.5 \mathrm{~Hz}, 3 \mathrm{H})$.

\section{HPLC of racemate of catalytic product}


HPLC: Chiracel AD-H, detected at 254 nm, eluent: n-hexane/2-propanol =97/3, flow rate $=1 \mathrm{~mL} / \mathrm{min}, 20^{\circ} \mathrm{C}$.

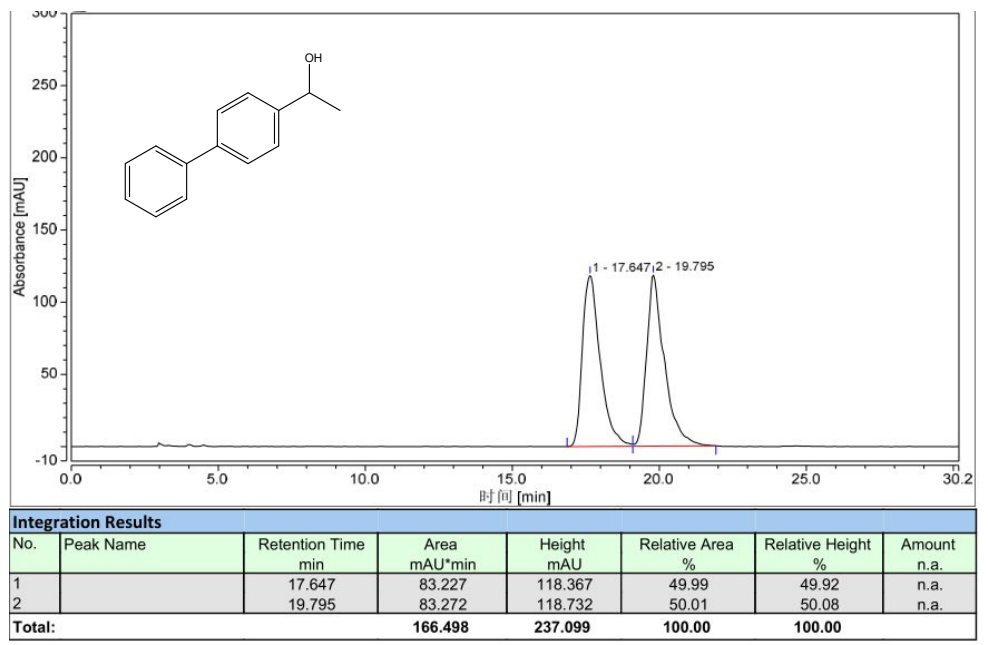

Fig. S28 HPLC of racemate of 1-([1,1'-biphenyl]-4-yl)ethan-1-ol.

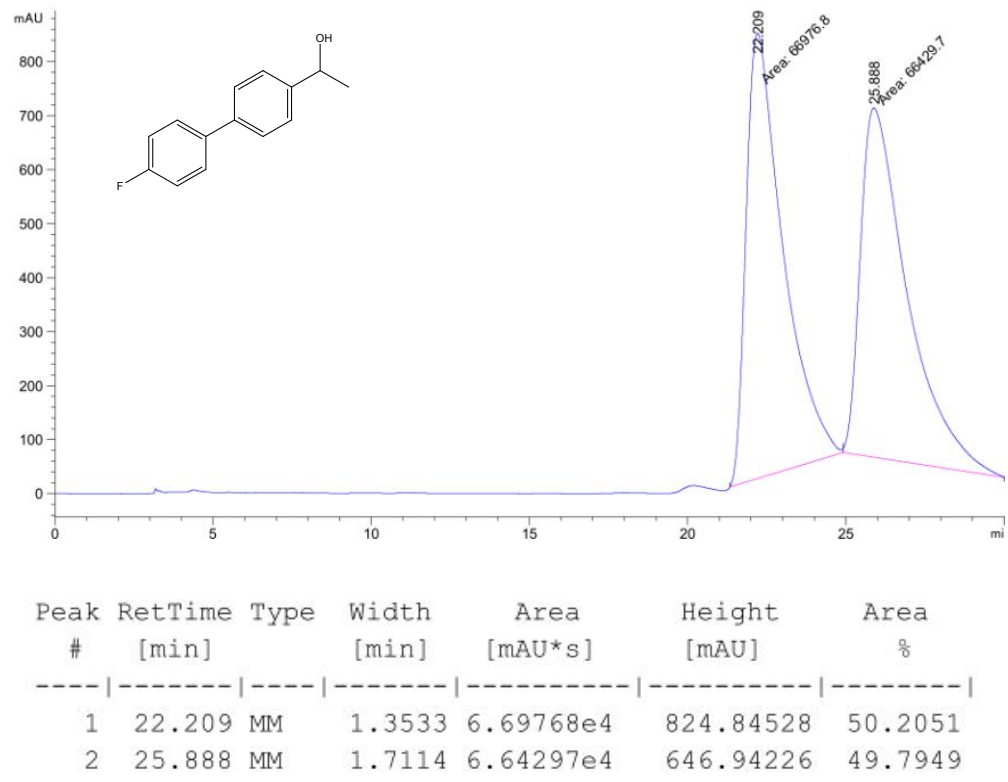

Fig. S29 HPLC of racemate of 1-(4'-fluoro-[1,1'-biphenyl]-4-yl)ethan-1-ol. 


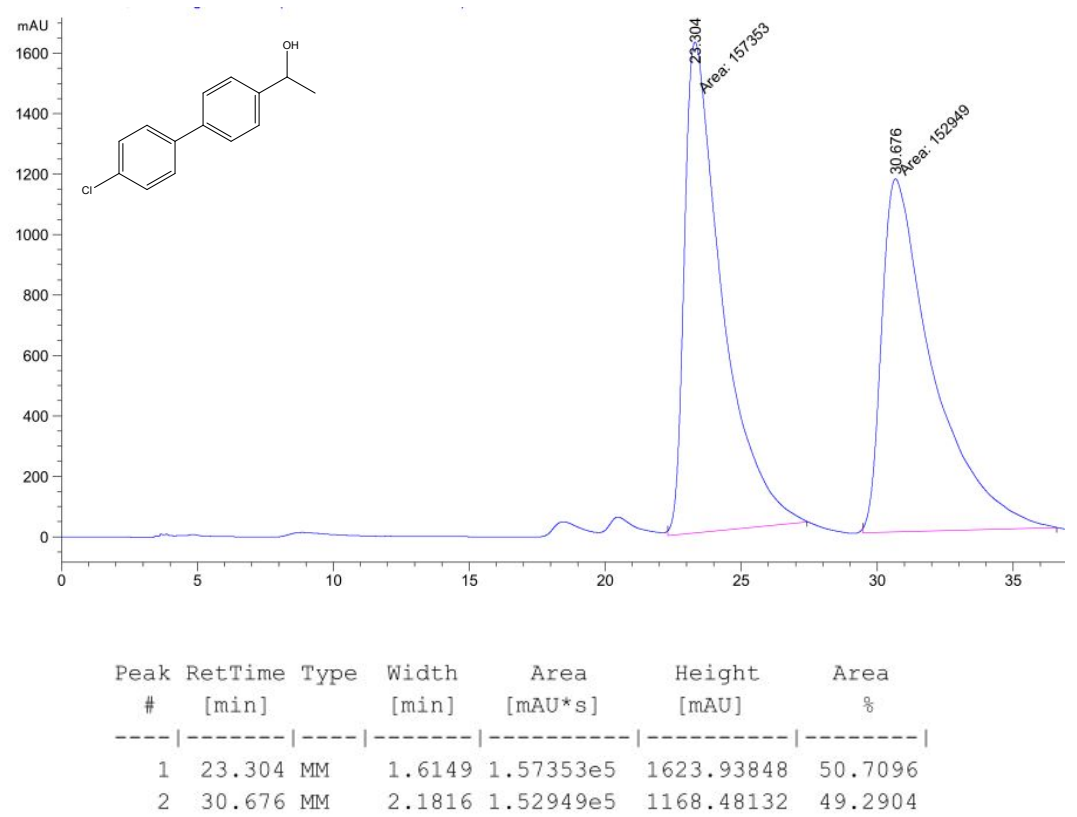

Fig. S30 HPLC of racemate of 1-(4'-chloro-[1,1'-biphenyl]-4-yl)ethan-1-ol.
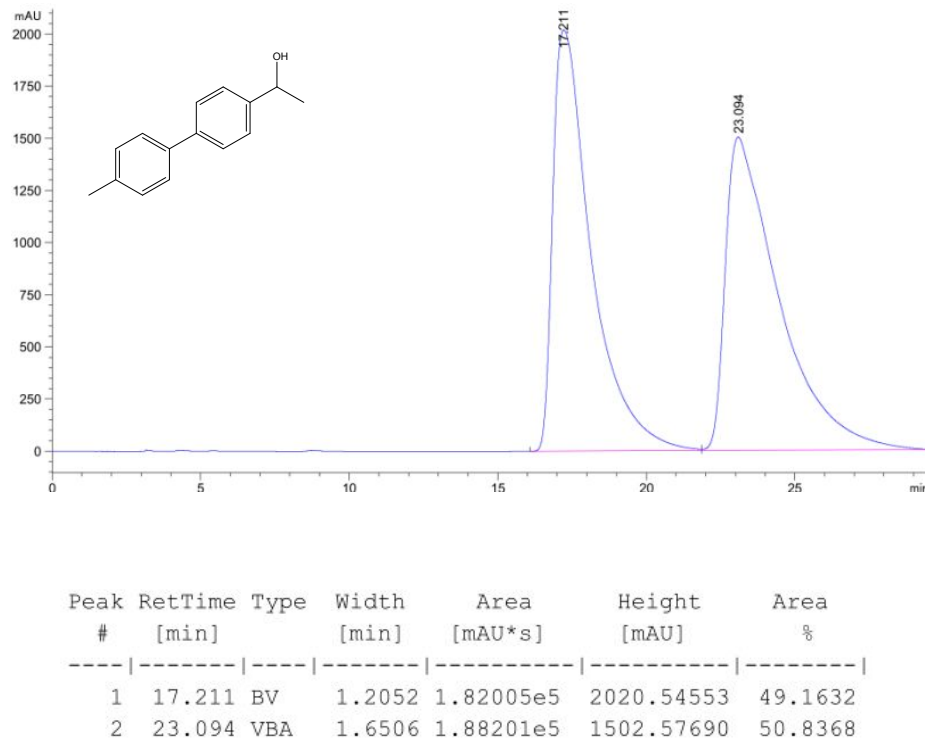

Fig. S31 HPLC of racemate of 1-(4'-methyl-[1,1'-biphenyl]-4-yl)ethan-1-ol. 

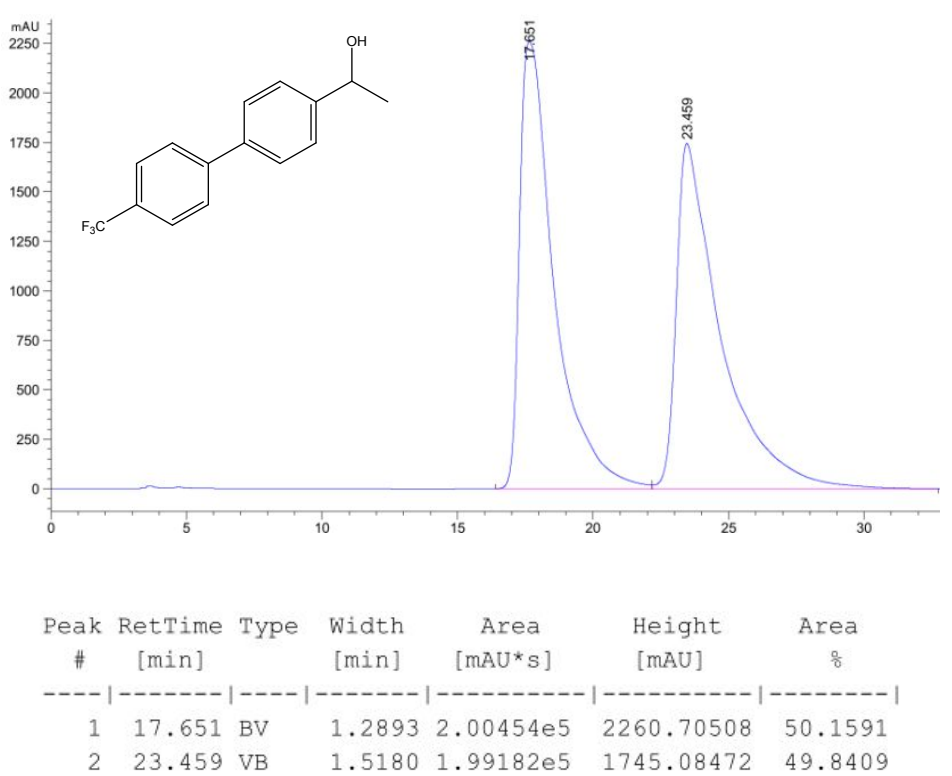

Fig. S32 HPLC of racemate of 1-(4'-(trifluoromethyl)-[1,1'-biphenyl]-4-yl)ethan-1-ol.

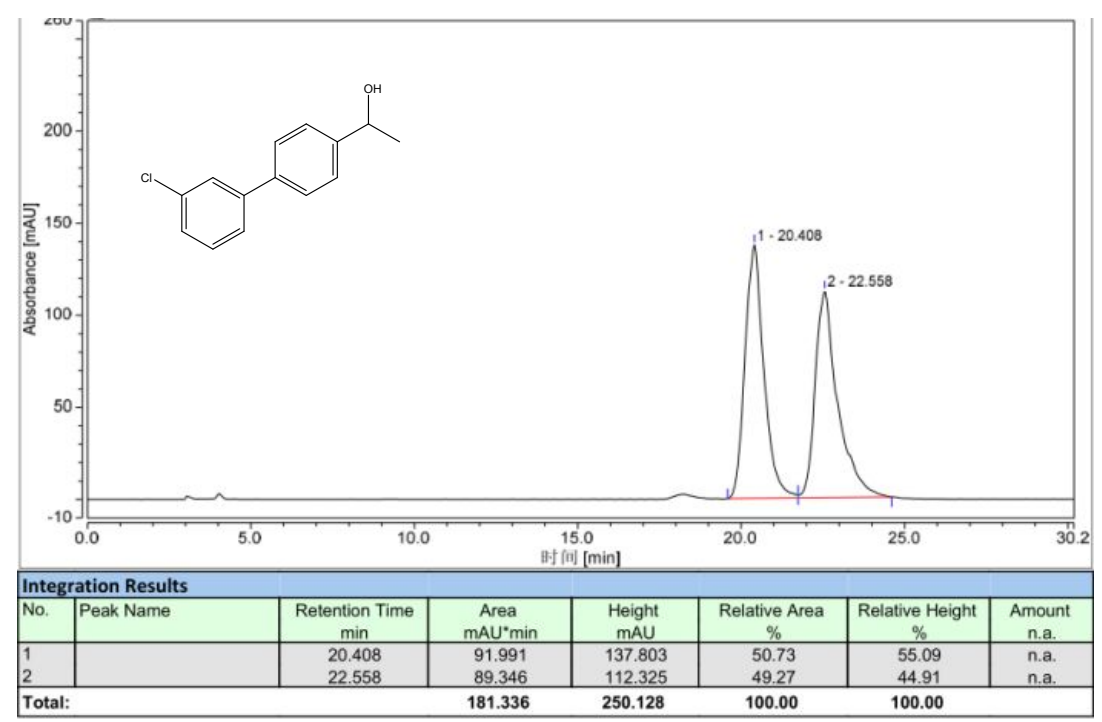

Fig. S33 HPLC of racemate of 1-(3'-chloro-[1,1'-biphenyl]-4-yl)ethan-1-ol. 


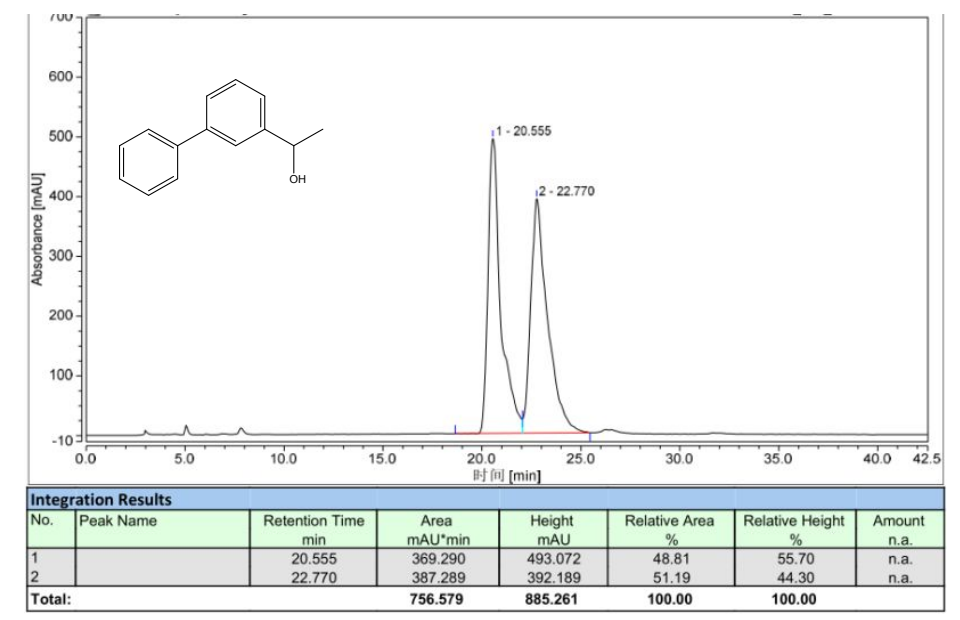

Fig. S34 HPLC of racemate of 1-([1,1'-biphenyl]-3-yl)ethan-1-ol.

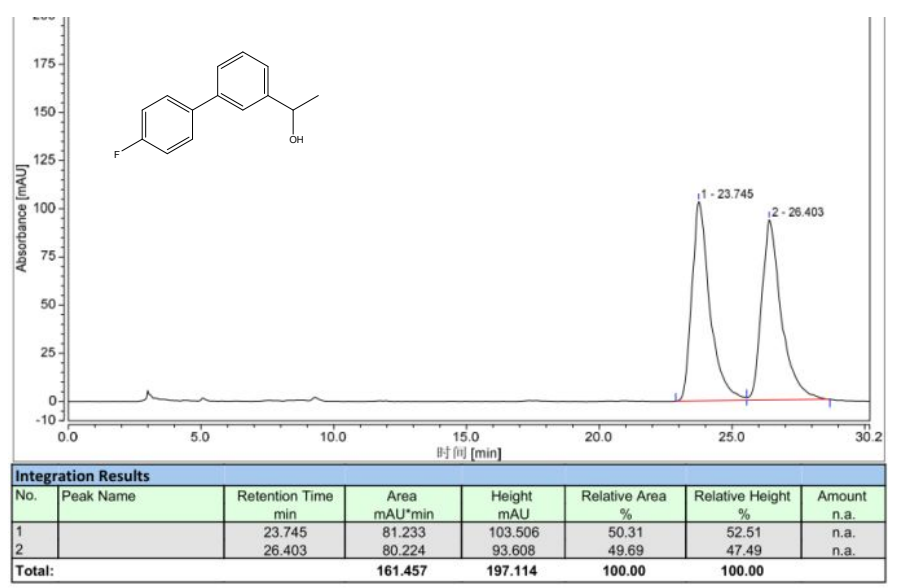

Fig. S35 HPLC of racemate of 1-(4'-fluoro-[1,1'-biphenyl]-3-yl)ethan-1-ol.

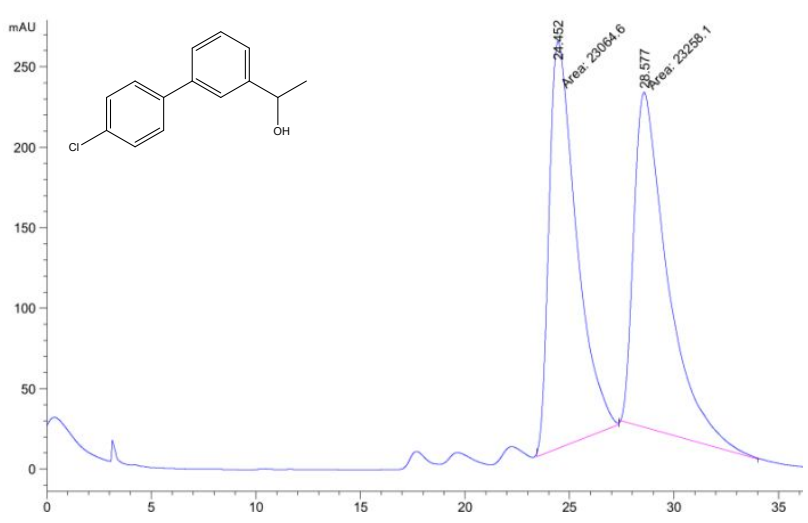




\begin{tabular}{|c|c|c|c|c|c|c|}
\hline $\begin{array}{c}\text { Peak } \\
\#\end{array}$ & $\begin{array}{c}\text { RetTime } \\
\text { [min] }\end{array}$ & Type & $\begin{array}{l}\text { Width } \\
\text { [min] }\end{array}$ & $\begin{array}{c}\text { Area } \\
{\left[\mathrm{mAU}^{\star} \mathrm{s}\right]}\end{array}$ & $\begin{array}{l}\text { Height } \\
\text { [mAU] }\end{array}$ & $\begin{array}{c}\text { Area } \\
\frac{0}{\gamma}\end{array}$ \\
\hline 1 & 24.452 & MM & 1.5195 & $2.30646 \mathrm{e} 4$ & 252.98747 & 49.7911 \\
\hline 2 & 28.577 & MM & 1.8642 & $2.32581 \mathrm{e} 4$ & 207.93201 & 50.2089 \\
\hline
\end{tabular}

Fig. S36 HPLC of racemate of 1-(4'-chloro-[1,1'-biphenyl]-3-yl)ethan-1-ol.

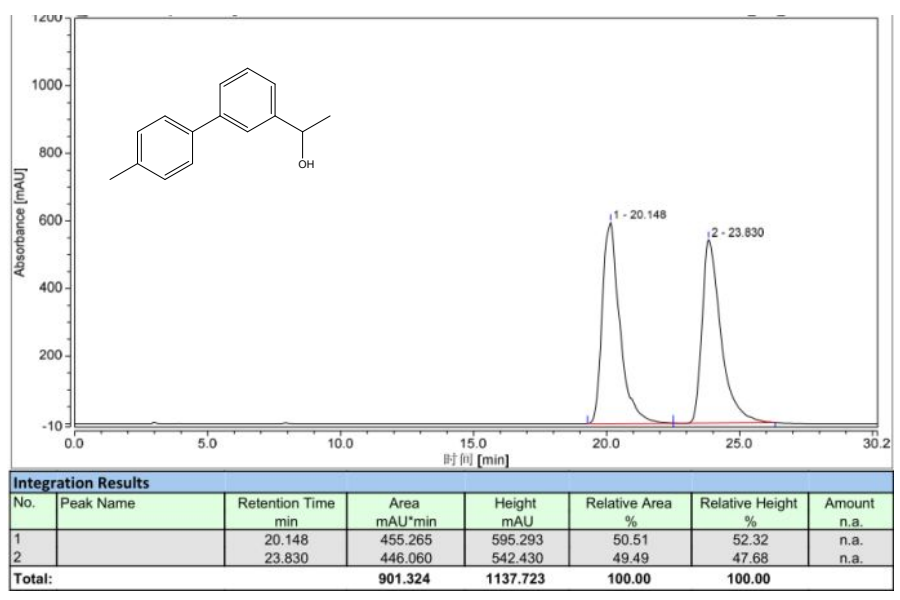

Fig. S37 HPLC of racemate of 1-(4'-methyl-[1,1'-biphenyl]-3-yl)ethan-1-ol.
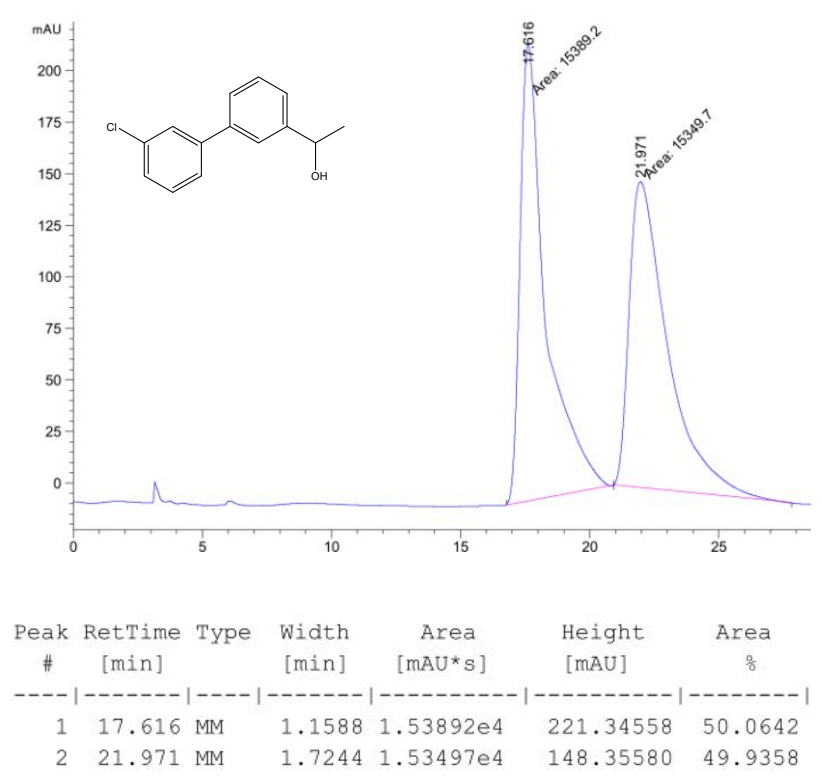

Fig. S38 HPLC of racemate of 1-(3'-chloro-[1,1'-biphenyl]-3-yl)ethan-1-ol. 


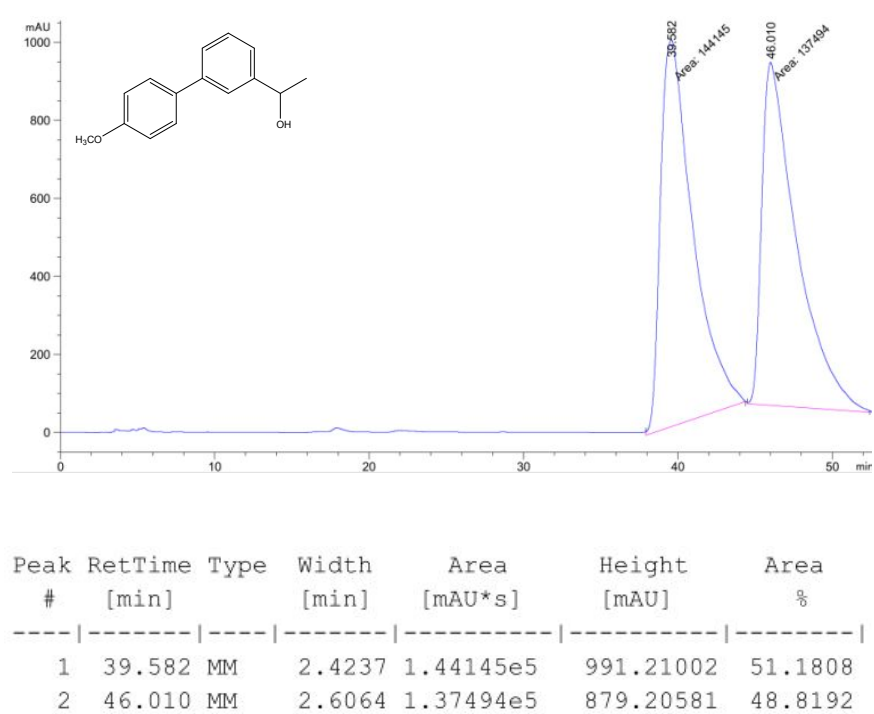

Fig. S39 HPLC of racemate of 1-(4'-methoxy-[1,1'-biphenyl]-3-yl)ethan-1-ol.

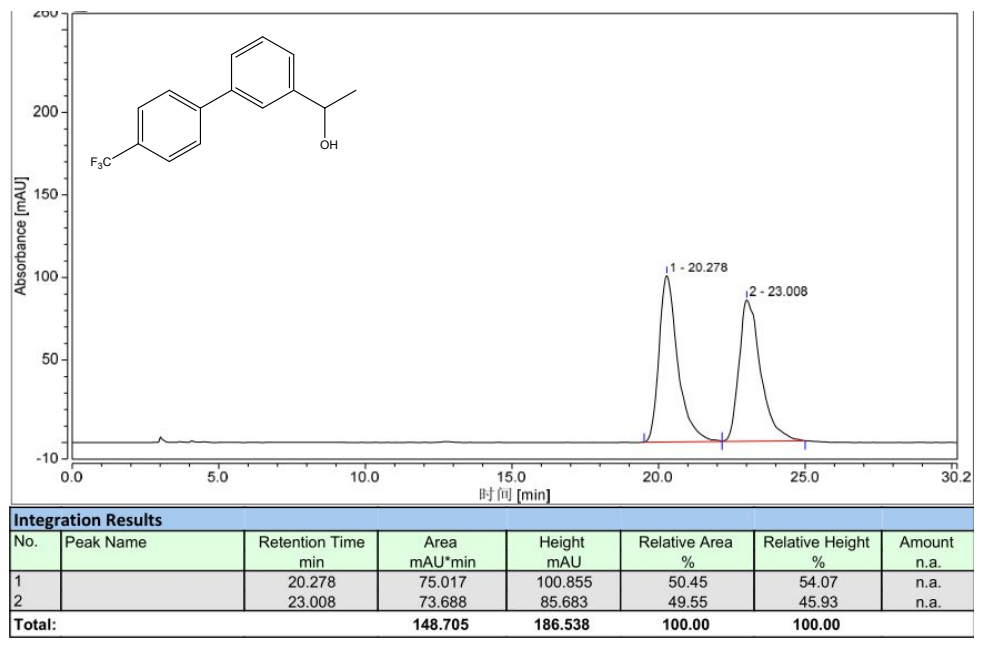

Fig. S40 HPLC of racemate of 1-(4'-(trifluoromethyl)-[1,1'-biphenyl]-3-yl)ethan-1-ol. 


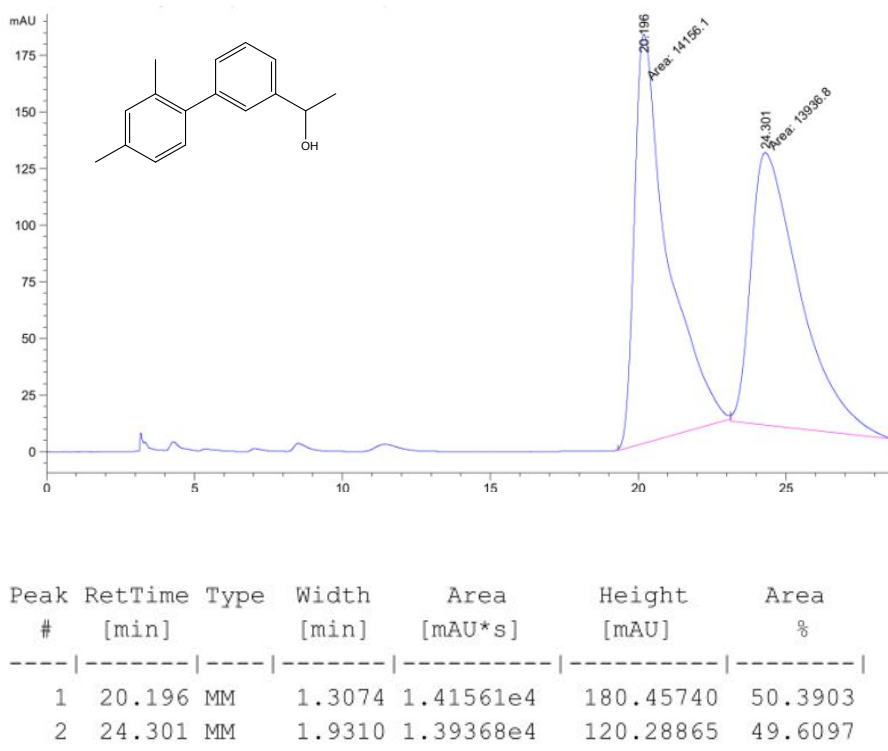

Fig. S41 HPLC of racemate of 1-(2'4'-dimethyl-[1,1'-biphenyl]-3-yl)ethan-1-ol.

\section{Notes and references}

(1) Li, X. J.; Lv C. N.; Jia, X. B.; Cheng, M.Q.; Wang, K.; Hu, Z. G. Nanoparticle Based on Poly(Ionic Liquid) as an Efficient Solid Immobilization Catalyst for Aldol Reaction and Multicomponent Reaction in Water. ACS Appl.

Mater. Interfaces, 2017, 9, 827-835. 